XI.

Aus dem Laboratorium der psychiatrischen Klinik zu Marburg (Prof. Tuczek).

\title{
Ueber die acut verlaufenden Erkrankungen an Dementia paralytica.
}

\author{
Von \\ Prof. Dr. Buchholz, \\ Oberarzt an der Irren-Anstalt Hamburg-Iriedrichsberg.
}

(Hierzu Tafel XIII.)

In den Monographien über die progressive Paralyse und in den Lehrbüchern der Psychiatrie finden wir beinahe regelmässig als eine besondere Art des Verlaufs dieses schweren Leidens jene Form der Erkrankung angeführt, welche als galoppirende Paralyse, als acute, oder foudroyante Paralyse bezeichnet wird. Von einzelnen Autoren, so z. B. von WeissSalgó ${ }^{\mathrm{I}}$ ) ist auf die Seltenheit dieser Verlaufsart hingewiesen worden, im allgemeinen jedoch gewinut man mehr den Eindruck, als ob dieser so rapide zum deletären Ende führende Krankheitsprocess doch nicht so ganz selten sei. In dieser Ansicht könnte man noch durch das Resultat einer Reihe von Statistiken bestärkt werden, da in vielen derselben die Zahl der nach einer kurzen Krankheitsdauer verstorbenen Paralytiker relativ hoch ist. Man muss jedoch berücksichtigen, dass die einzelnen Statistiken nicht so ohne weiteres mit einander verglichen werden können, da sie von sehr verschiedenartigen Gesichtspunkten aus angestellt sind. So haben z. B. die einzelnen Autoren den Beginn der Erkrankung sehr verschieden angesetzt, je nachdem sie die mehr allgemeinen Prodromalerscheinungen der Erkrankung bereits in die Krankheitsdauer eingerechnet haben, oder nicht. Wie schwer es überhaupt

1) Compendium der Psychiatrie. II. Auflage.

Archiv f. Psychiatrie. Bd. 36. Heft 2. 
ist, sichere anamnestische Angaben über die ersten Erscheinungen dieses oftmals so vollkommen schleichend einsetzenden Leidens zu erhalten, ist allgemein bekannt. Es würde sicherlich verkehrt sein, wenn man ganz schematisch alle die Erkrankungen an Paralyse, in denen der Kranke bald, sagen wir z. B. im Laufe eines halben oder auch eines ganzen Jahres dahingerafft wird, der acuten Paralyse zuzählen wollte. Ausscheiden müssten aus dieser Zahl ohne weiteres alle die Kranken, welche nicht ihrer Paralyse oder den mit dieser enge verbundenen Complicationen, sondern einem intercurrenten, mit ihrer Paralyse in keinem directen Zusammenhange stehenden Leiden erliegen, oder durch einen Unglücksfall zu Grunde gehen. $\mathrm{Zu}$ diesen letzteren würden z. B. auch jene Fälle zu rechnen sein, in welchen ein Kranker in Folge Verlegung der Luftwege durch Speisemassen sein Leben verliert. Gewiss sind ja auch in diesen Fällen die durch die Erkrankung an Paralyse bedingten Störungen die Ursachen für das Eintreten eines derartigen Unglücksfalles, schliesslich ist der Tod doch aber immer noch nicht eine directe Folge der Paralyse. Aehnlich würden die Verhältuisse bei einem Tode durch Suicidium liegen. In gleicher Weise dürfte die Entscheidnng leicht sein, wenn es sich um wirklich vollkommen intercurrente Erkrankungen, wie z. B. um eine Infection an Diphtherie handelt. Bei einer Reibe von Affectionen wird es aber sehwierig sein, den directen Antheil der Paralyse an dem zum Tode führenden Processe zu bestimmen, so z. B. bei den Phlegmonen, die sich an relativ harmlose Verletzungen anschliessen, und bei dem Decubitus mit seinen Folgen.

Ebenso müssten von dieser Zahl alle jene Kranken abgezogen werden, die bereits vor Ausbruch der Paralyse an einem schweren, schon an und für sich zum Tode führenden Leiden erkrankt waren, wie z. B. an schweren Erkrankungen des Herzens, an Tuberculose oder Nephritis. Auch bei derartigen Kranken wird die Erkrankung an Paralyse die Widerstandsfähigkeit des Organismus herabsetzen, aber doch nicht als solche den tödtlichen Ausgang bedingen. Es würden dann jene Kranken übrig bleiben, die der Paralyse als solcher, resp. den durch sie direct bedingten Complicationen, zu denen ich also nicht nur die rein terminalen Processe rechnen möchte, erliegen. Ich möchte demnach die Grenzen nicht so enge ziehen wie Heilbronner ${ }^{1}$ ), der in allerdings ganz consequenter Weise nur dann von einem Tode an Paralyse spricht, wenn der Kranke an Erschöpfung des Centralnervensystems oder im paralytischen Anfalle zu Grunde geht. Ich gebe dabei ohne weiteres

1) Ueber Krankheitsdauer und Todesursachen bei der progressiven Paralyse. Zeitschr. für Psych. Bd. 51. 
zu, dass damit dem subjectiven Ermessen ein gewisser Spielraum gelassen wird.

Weiterhin wird es sich fragen, ob nach dem Ausscheiden aller dieser Fälle die sämmtlichen übrigbleibenden ohne weiteres der acuten resp. galoppirenden Form der Paralyse zuzurechnen sind, ob also die Krankheitsdaner allein für die Classificirung maassgebend sein soll, oder ob nicht etwa der ganze Verlauf, die Art und die Combination der einzelnen Symptome und eventuell auch der pathologisch anatomische Befund einer derartigen Entscheidung zu Grunde gelegt werden soll.

Es würde vorerst einmal zu erörtern sein, was wir unter der Bezeichnung acuter, galoppirender Paralyse verstehen wollen. Eine Beantwortung dieser Frage erscheint durchaus nothwendig, wenn eine Verständigung möglich sein soll, da die von den einzelnen Autoren gegebenen Schilderungen dieser Verlaufsart der Paralyse in manchen, und zwar nicht ganz unwichtigen Punkten von einander abweichen. Es könnte hiergegen eingewandt werden, dass es sich hierbei nur um einen Streit um Worte handelt, dass eine genauere Präcision dieser Begriffe überhaupt nicht nothwendig sei. Ich glaube, dass dieser Einwand nicht zu Recht besteht, da eine präcise Umgrenzung der einzelnen Typen des Krankheitsverlaufes, unbeschadet der verschiedenartigen Uebergangsbilder, schon im Interesse einer schnellen Verständigung erwünscht sein muss.

Es kann nicht meine Sache sein, hier die sämmtlichen von den einzelnen Autoren über diese Art des Krankheitsverlaufes der Paralyse entworfenen Schilderungen wiederzugeben und einer Kritik zu unterziehen. Vor allem möchte ich von der ganzen älteren Literatur absehen. Eine eingehende Besprechung derselben würde ausserordentlich viel Raum beanspruchen und in vielen Beziehungen doch zu unbefriedigenden Resultaten tühren, da bei einer Reibe von Fällen die Schilderung des Krankheitsverlaufes und des pathologisch anatomischen Befundes eine sichere Diagnose nicht gewährleistet.

So möge hier nur die Auffassung einiger der neueren Autoren angeführt werden.

Mendel ${ }^{1}$ ) entwirft von der galoppirenden Paralyse im wesentlichen folgendes Bild: „Der Kranke bietet die Erscheinungen einer agitirten Manie, die sich meist sehr schnell bis zu dem höchsten Grade der Manie, selbst des Furors steigert. Die motorischen Störungen können dabei im Aufange unbedeutend sein. Forscht man genauer nach den Antecedentien,

1) Die progressive Paralyse der Irren. Berlin 1880. Hirschwald. 
so pflegt sich zu zeigen, dass der anscheinend bei einem Gesunden hervortretenden Psychose eine häufig weit zurückreichende Reihe von Vorläufer-Symptomen vorausgegangen ist. - Characterumwandlungen, auffallende, den Angehörigen häufig nicht erklärliche Handlungen, Sprachstörungen, vorübergehende Aphasie, Ohnmachts- oder selbst ausgebildete apoplectiforme Anfälle. - Zuweilen bilden auch derartige apoplectiforme oder epileptiforme Anfälle den Uebergang des Prodromalstadiums in den acut verlaufenden Process. Der weitere Verlauf der ausgesprochenen Erkrankung bestätigt sehr bald, dass es sich um eine schwere organische Gehirnerkrankung handelt. Die höchsten Grade maniacalischer Exaltation verbinden sich mit apoplectiformen oder epileptiformen Anfällen. Pulsbeschlemigung, Temperatursteigerung, Nahrungsverweigerung, Albuminurie, Diarrhoeen, schneller Verfall der Körperkräfte, Sprachstörungen stellen sich ein, oder nehmen derartig schnell zu, dass der Kranke vollkommen unverständlich wird. Der Kranke geht im paralytischen Anfall oder unter den Erscheinungen der Erschöpfung zu Grunde. Die Dauer dieses Zustandes kann 14 Tage bis 6 Wochen betragen. Zuweilen treten schnell vorübergehende Remissionen auf."

Wir sehen somit, dass Mendel auch jene Fälle zur galoppirenden Paralyse rechnet, in welchen schon längere Zeit mehr oder minder ausgeprägte Krankheitserscheinungen - Characterumwandlungen, auffallende Handlungen, Ohnmachtsanfälle etc. - den stürmischen Symptomen vorausgegangen sind. Es würde sich in diesen Fällen eigentlich um chronisch beginnende Leiden handeln, die in einer acut einsetzenden Phase schwerster Krankheitserscheinungen zum Tode führen.

In seiner in der Eulenburg'schen Realencyclopädie (III. Auflage) enthaltenen Abhandlung über Paralyse definirt Mendel allerdings die galoppirende Paralyse als diejenige Form, in welcher die Krankheit von ihrem Ausbruch an in wenigen Wochen oder Monaten unter heftigster Steigerung der geschilderten Symptome zum Tode führt.

v. Krafft-Ebing ${ }^{1}$ ) stellt der ungeheuren Mehrzahl der chronisch verlaufenden Erkrankungen an Paralyse jene seltenen Fälle gegenüber; in welchen die Krankheit binnen Monats- bis höchstens Jahresfrist abläuft. (acute und galoppirende Paralyse).

Kraepelin²) bezeichnet als agitirte Paralyse diejenige Verlaufsart der expansiven Form, bei welcher ausgeprägtere manische und deliriöse Erregungszustände das Krankheitsbild beherrschen.

1) Die progressive allgemeine Paralyse. Wien 1894. Hölder.

2) Psychiatrie. Lehrbuch für Studirende and Aerzte. V. Auflage. Leipzig 1896. 
"Die schwersten Fälle der agitirten Paralyse hat man bisweilen mit dem Namen der galoppirenden Paralyse belegt. Es handelt sich dabei um einen überaus raschen, tödlichen Verlauf der Erkrankung unter den Erscheinungen hochgradigster psychischer und nervöser Erregung mit plötzlichem Zusammenbruch. Dieses Krankheitsbild ist es, welches ohne Zweifel bisweilen mit unter der Bezeichnung des Delirium acutum zusammengefasst worden ist."

In ähnlicher Weise spricht Weiss-Salgó von Fällen von überstürztem rascheren Verlaufe, die oft schon nach einigen Hlonaten oder nach einem Jahre am Ende des Decursus angekommen sind. Er fährt dann fort: "Und endlich ist noch auf einige Ausnahmefälle aufmerksam zu machen, in welchen die Affection mit furibunder Tobsucht beginnt, und in welchen die Tobsucht in ungebrochener Kraft Tag und Nacht durch Tage und Wochen andauert, nur mit der totalen Erschöpfung der Kranken endigt und nach jühem, kaum wochenlangem Verlaufe den tödlichen Ausgang herbeiführt." Diese Fälle sog. "foudroyante Paralyse" gehören wohl zu den seltensten Ausnahmen.

Binswanger ${ }^{x}$ ) geht in dieser Trennung der Verlaufsarten der schnell zum Tode führenden Paralysen noch weiter. Er beschreibt in seiner, allerdings von einem ganz besonderen Gesichtspunkte ausgehenden Eintheilung als eine dritte Gruppe der Paralysen die sog. galoppirende Form, welche nach kurzen oder länger dauernden Vorläufererscheinungen im Initialstadium unter raschem Anstieg der psychischen und somatischen Krankheitserscheinungen zum Tode führt. Als vierte Gruppe bezeichnet er eine zweifelsohne sehr seltene Krankheitsform, bei welcher, auch bei genauester Nachforschung das Bestehen von paralytischen Krankheitserscheinungen vor Ausbruch des acut verlaufenden Krankheitszustandes sich nicht nachweisen lässt.

Es ist nicht zu verkennen, dass die Aufstellung dieser letzten Gruppe beinahe unerfüllbare Anforderungen an den Arzt stellt, und dass immer nur in sehr wenigen Fällẹn der Nachweis wird geführt werden können, dass bis zum Ausbruche der so schnell zum Tode führenden Erkrankung Krankheitserscheinungen nicht vorhanden gewesen sind. Es ist dies schon deswegen so sehr schwer, weil es gewisse Krankheitserscheinungen in dem Prodromalstadium der progressiven Paralyse giebt, die sich dem Kranken und seiner Umgebung garnicht und nur sehr wenig bemerkbar machen, so dass sie nur sehr selten einmal entdeckt werden. Es ge-

1) Die pathologisehe Histologie der Grosshirnrindenerkrankung bei der allgemeinen progressiven Paralyse mit besonderer Berüeksichtigung der acuten und Frühformen. Jena 1893. 
hören zu diesen Symptomen unter anderen die Erscheinungen an den Pupillen, die, wie uns Thomsen') gelehrt hat, schon jahrelang dem Ausbruche der schwereren Erscheinungen der Paralyse vorangehen können. Schliesslich würde aber auch das Fehlen aller Krankheitserscheinungen vor dem Ausbruche der stürmischen Symptome nicht beweisen, dass nicht vielleicht doch schon seit längerer Zeit pathologische Processe innerhalb des Centralnervensystems vorhanden gewesen sind. Wir können diese Annahme nicht von der Hand weisen, da sicherlich nicht alle der Dementia paralytica angehörigen pathologischen Veränderungen obne weiteres sofort nachweisbare klinische Krankheitssymptome hervorrufen. Finden wir doch auch bei Paralytikern, welche in einer tiefen Remission an einer intercurrenten Krankbeit sterben und zur Zeit des Todes relativ wenig Krankheitserscheinungen zeigen, weit ausgedehnte Veränderungen innerhalb des Centralnervensystems.

Voisin2) schliesslich, auf dessen Honographie ich gerne noch zurückgreifen möchte, schildert mehrfache Verlaufsarten der Paralysie générale aiguë. In der einen Reihe der Fälle gehen die Kranken im Verlaufe von einer Woche bis zu einem Monat nach plötzlichem Ausbruch des Leidens bei einem bis dahin gesunden Individuum unter stürmischen Krankheitserscheinungen zu Grunde. In einer zweiten Reihe von Fällen tritt der deletäre Complex bei Kranken auf, die schon vorher Krankheitserscheinungen darboten. An dritter Stelle macht er auf jene Krankheitsform aufmerksam, bei welcher von vornherein der Symptomencomplex des sogenannten acrten Deliriums die Scene beherrscht, und weist hierbei auf die Schilderungen Calmeil's3) hin.

Es herrscht somit in dem Gebrauche der Bezeichnung nacute, foudroyante, galoppirende Paralyse" eine gewisse Willkür. Ich will hier ganz von allen jenen Fällen absehen, in welchen nach einem Prodromalstadium von ausgesprochen paralytischen Symptomen - Characterumwandlungen, unerklärliche Handlungen, Ohnmachtsanfälle etc. - der turbulente Krankheitsprocess einsetzt. Es dürfte, wie ich bereits bemerkte, richtiger sein, hier von Paralysen zu sprechen, die chronisch begimnen, um dann, sei es in Folge nachweisbarer Schädigungen, sei es ohne erkennbaren Grund in ein derartig acutes Stadium eintreten. Es würden also hier nur jene bei bis dahin gesunden Personen einsetzenden acuten Fälle von Erkrankung an Paralyse in Betracht zu ziehen sein. Es wird allerdings, worauf ich bereits aufmerksam machte,

1) Ueber paralytische Frühsymptome. Zeitschr. für Psych. Bd. 52.

2) Traité de la paralysie gènérale. Paris 1879.

3) Traité des maladies inflammatoires du cervean. Paris 1859. 
nur in sehr wenigen Fallen der Nachweis zu erbringen sein, dass absolut gar keine Krankheitserscheinungen dem acuten Krankheitsprocesse vorausgegangen sind.

Es ist von den einzelnen Autoren bereits darauf hingewiesen worden, dass die acuten Formen der Paralyse sehr verschiedenartig verlaufen können, dass es sich einmal um eine Abkürzung des ganzen sonst so chronischen Processes handelt, und dass andererseits die Erkrankung eine besondere Färbung erhalten, eine Verschiebung nach der Richtung des acuten Deliriums hin erfahren kann. Nach dem allgemeinen Eindruck hatte auch ich das Gefühl, dass sich die acut verlaufenden Fälle von Paralyse wirklich in dieser Weise gruppiren lassen; es musste mir jedoch darum zu thun sein, an einem grösseren Materiale die Richtigkeit dieser Anschauung zu prüfen. Sodann schien mir auch die Frage nach der Häufigkeit dieses rapid zum Tode führenden Krankheitsprocesses von erheblichem Interesse zu sein; ich selbst hatte angenommen, dass diese schnell verlaufenden Paralysen recht selten vorkommen. Ich suchte vorerst einmal festzustellen, wieviel paralytisch Kranke der hiesigen (Marburger) Anstalt bereits im ersten Jahre ihres Leidens verstorben sind. Gewiss ist ein derartiges Vorgehen ganz schematisch, ich glaubte aber auf diese Weise vorerst einmal eine Grundlage zu gewinnen, auf welcher sich dann würde weiter bauen lassen.

Es fanden in der hiesigen (Marburger) Anstalt seit deren Eröffnung (8. 6. 1876 bis sum 31. 3. 1900) 335 paralytisch kranke Männer Aufnahme. In dieser Zahl sind einige Kranke nicht enthalten, die sonst wohl vielfach als paralytisch bezeichnet werden. Es handelt sich dabei uma Kranke, die ein Krankheitsbild aufwiesen, wie es von Wickel1) gezeichnet ist. Ausserdem ist der vor circa 2 Jahren verstorbene Kranke J., dessen Krankengeschichte seinerzeit Tuczek ${ }^{2}$ ) veröffentlicht hat, hier nicht mit eingerechnet, da es sich bei ihm, wie der spätere Verlauf der Erkrankung zeigte, kaum um eine progressive Paralyse gehandelt haben dürfte. Sodann sind bier 2 Kranke nicht mitgezählt, bei welchen eine sichere Diagnose nicht gestellt werden konnte; beide Kranken erlagen ihren Leiden kurze Zeit nach ihrer Aufnahme in die Anstalt, sie boten den Symptomencomplex des acuten Deliriums dar. Ich werde auf die Geschichte dieser beiden Kranken später noch zurückkommen.

1) Casuistische Beiträge zur Differentialdiagnose zwischen Lues cerebrj diffusa und Denentia paralytica. Dieses Archiv Bd. 30.

2) Beiträge zur pathologischen Anatomie und zur Pathologie der Dementia paralytica. Berlin 1887. 
Von den 335 paralytisch kranken Männern erlagen 302 ihrem Leiden sicher est später als ein Jahr uach dessen Ausbruch. Von den übrigen 33 Männern können 9 hier nicht weiter in Betracht kommen. Bei einem Theile derselben fehlt die Anamnese vollkommen oder ist ganz uugenügend; mehrfach handelte es sich hier um Leute, die von den Polizeiorganen aufgegriffen waren. Ein anderer Theil dieser Kranken schied aus der Behandlung aus und entschwand unserem Gesichtskreise. Wahrseheinlich hat es sich übrigens auch bei diesen 9 Kranken um chronisch verlaufende Erkrankungen gehandelt. Es spricht hierfür der ganze Befund und der Verlauf, soweit er in der Anstalt beobachtet wurde. So waren die ohne Anamnese aufgenommenen Kranken bereits in erheblichem Grade verblödet, während die anderen Kranken, welche aus der Anstalt ausschieden, das bekannte Bild des chronischen Paralytikers zeigten, resp. in eine Remission eingetreten waren. Es würde somit die Zahl der Kranken, welche erst nach Jahresfrist za Grunde gingen, um diese 9 Kranken vermehrt werden können, ohne dass damit ein Fehler in der Berechnung eingeführt würde. Aber auch wenn diese 9 Fälle ganz aus der Berechnung herausgelassen werden, erseheint der Procentsatz der Kranken, die in dem ersten Jahre nach Ausbruch ihres Leidens der Paralyse erlagen, sehr gering. Es würden von 326 paralytisch kranken Männern nur $24 \mathrm{im}$ ersten Jahre nach dem Ausbruche der Paralyse verstorben sein, also nur 7,36 pCt. Diese Ziffer ist ganz ausserordentlich niedrig gegenüber den sonstigen Angaben. So zählt

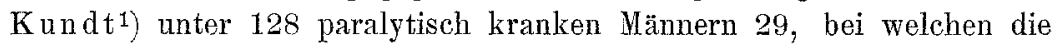
Krankheitsdauer unter $1 \mathrm{Jahr}$ betrug $=22,6$ pCt. Müller ${ }^{2}$ ) fand sogar unter allerdings nur 55 Paralytikern 13 - 23,6 pC.t, die im ersten Jahre ihres Leidens zu Grunde gingen. Sprengle ${ }^{3}$ ) führt in seinen Tabellen unter 243 Paralytikern 44 auf, welche innerhalb des ersten Krankheitsjahres verstarben $=18,1 \mathrm{pCt}$. Einen ähnlich hohen Procentsatz erbält Heilbronner ${ }^{4}$ ) aus seinen Berechnungen, er fand unter 403 paralytisch kranken Männern 78, die im ersten Jahre der Erkrankung aus dem Leben schieden $=19,35 \mathrm{pCt}$. - Wesentlich niedrigere Zahlen

1) Statistisch casuistische Mittheilung zur Kenntniss der Paralyse. Zeitschr. für Psych. Bd. 50.

2) Statistische Betrachtungen über allgemeine Paralyse. Zeitschr. für Psych. Bd. 54.

3) Beitrag zur Statistik etc. der allgemeinen progressiven Paralyse etc. Zeitschr. für Psych. Bd. 56.

4) Ueber Krankheitsdauer und Todesursachen bei der progr. Paralyse. Zeitschr. für Psych. Bd. 51. 
finden sich bei Mendel1) und Oebeke ${ }^{2}$ ). Ersterer führt in einer Tabelle unter 95 Kranken 8 mit einem Krankheitsverlauf unter 1 Jahre auf, $7,36 \mathrm{pCt}$., letzterer unter 70 Kranken $6=8,28 \mathrm{pCt}$.

Von den hiesigen 24 Kranken, die im ersten Jabre des Bestehens der Paralyse verstorben sind, würden nach den vorstebend erörterten Gesichtspunkten alle die auszuscheiden sein, welche nicht der Paralyse, sondern Complicationen, welche mit ihrer Erkrankung an Paralyse nicht in directem Zusammenhange stehen, erlegen sind. Es starben von diesen Kranken 3 (A. W. und Sch.) an Tuberculosis pulmonum; bei allen diesen bestand die Tuberculose bereits längere Zeit vor Ausbruch der Paralyse. Die Krankheitsdauer der Paralyse betrug in diesen Fällen 6, 9 und 10 Monate. Ihr Verlauf war dabei derartig, dass man nur von einer chronischen Erkrankung sprechen konnte. Denselben Eindruck gewamn man aus den Ergebnissen der Autopsie. Das Rückenmark des einen dieser Patienten, des am 3. December 1888 verstorbenen Kranken A. konnte noch einer Untersuchung unterzogen werden. Dieselbe ergab folgenden Befund: Starke, ausgedehnte, über die ganze Länge des Rückenmarkes sich erstreckende Degeneration in den HStr., dieselbe macht durchaus den Eindruck eines chronischen Processes, auffallend war nur die sehr grosse Menge der daselbst vorhandenen Körnchenzellen. Degeneration der H.W., Schwund des Fasernetzes in den Clarke'schen Säulen, geringe Degeneration in den S.Str.

Von einer Wiedergabe der Besonderheiten nicht bietenden Krankengeschichten, glaube ich absehen zu können.

Von den übrigbleibenden 21 Fällen scheiden 2 (Pat. J. und Pf.) aus, welche an Blasenrupturen zu Grunde gingen; ein dritter Kranker Br., dessen Krankengeschichte als Fall XV von Tuczek veröffentlicht ist, verstarb nach circa $3 / 4$ jähriger Krankheitsdauer in Folge von Erstickung. Ein 4. Kranker versehied am 2. Tage nach seiner Aufnahme in die Anstalt (5. Mai 1892) in Folge von Aspiration ron Eitermassen in die Luftwege. Bei ihm hatte die Erkrankung eine Dauer von ungefähr 5 Monaten. Ein 5. Kranker B. ging 1 Monat nach seiner Aufnahme an einer eitrigen Pericarditis zu Grunde. Ein 6. Patient schliesslich ging an einer Embolie der Arteria coronaria sinistra verloren.

Es würden somit noch 15 weitere Fälle verbleiben, in welchen die Kranken innerhalb des ersten Jahres ihrem Leiden erlagen.

Bei 9 von dieseu Patienten verlief die Erkrankung zwar sehr schnell,

1) Joc. cit.

2) Ueber Pupillenreaction und einige andere Erscheinungen bei der progress. Paralyse. Zeitschr. für Psych. Bd. 50. 
sie wich jedoch im übrigen in ihrem Verlaufe von dem gewöhnlichen Bilde der Paralyse nur insofer'n ab, als eben der ganze Process ausserordentlich abgekürzt war. Es dürfte daher rollkommen genügen, wenn hier die Krankengeschichten nur ganz aphoristisch wiedergegeben werden.

N., geb. 5. Juli 54, aufg. 9. Sept. 93, gest. 6. Dec. 93. Ein Bruder an Paralyse gest.; normale Entwickelung, im wesentlichen immer gesund. Januar 93. Verdauungsstörungen, zugleich allerlei psychische Aberrationen, hypochondrische Vorstellungen, Selbstanlilagen. August 93 heitere Erregung, Grössenideen, sinnlose Handlungen. Stat. Pupillen reagiren, Vibriren im Facialisgebiet, Silbenstolpern, Fehlen der P. S. R., Euphorie, Grössenideen, 9.-21. IX. mehrere paralytische Anfälle, in der Zwischenzeit soporös. Schnelle Zunahme der Verblödung. Vom 2. 12. bis zum Exitas gehäufte Anfälle. Gehirngewicht 1400, in den H. Str. des R. M. graue Verfärbungen.

M., geb. 26. Aug. 69, aufg. 16. Sept. 96, gest. 10. Jan. 97. Normale Entwickelung, solider Mann, hatte als Schriftsetzer riel mit Blei zu arbeiten. Frühjahr 96. Veränderung der Sprache, Sommer: Verstimmung, vielfache hypochondrische Klagen, Kopfschmerzen, Unsicherheit beim Gehen, Urinträufeln, Stat. Graue Gesichtsfarbe, Bleisaum, träge Lichtreaction, lebhafte P. S. R., Analgesie, Romberg, taumelnder Gang. Aengstliche Verstimmung, hypochondrische Vorstellungen, nach einigen Tagen motorische Erregung. 6. XI.Anfall, typisch hysterischerArt, arc de cercle, grands monrements. Ende September stärkere ängstliche Erregung. 3.X. 2 hysteriforme Anfälle. Schnelle Verblödung bei mittlerer Stimmungslage, körperlicher Verfall, Decubitus, finale Pneumonie. Gehirngewicht 1200. Verdickung der weichen Häute, Atrophie im Gebiete des Stirnhirns, im Nucleus caudatus ein kleiner Erweichungsherd, Ependymgranulationen.

0., geb. 5. Mai 50, aufg. 9. Mai 80, gest. 26. Febr. 81. Vater Potator. Als Soldat 3 Monate im Lazareth wogen Leistendrüsen-Anschwellung. Seit April 80 verstimmt, Mitte Mai tobsüchtig. Pupillen-Reaction erhalten. P.S.R. vorhanden, starke Sprachstörungen, gehobene Stimmung, motorische Unruhe, Grössenideen. 1. 6. paralytischer Anfall, bald darauf ruhig, still, arbeitet. 13. 1. und 19. 1. 81 Anfall, in der Zwischenzeit deprimirt. Depression blieb bestehen. Apathie, zunehmende Demenz. Februar Dämpfung L. H. U. gangranöser Fötor. Gehirngewicht 1280. Trübung der Meningen, Verwachsungen der weichen Häute mit der Rinde des Stimhirns, Ependymitis granulosa, Hydrops ventriculorum. Py. S. Str. rosig verfärbt. Lungengangrän.

W., geb. 26. Dec. 37, aufg. 7. Mai. 89, gest. 15. Septr. 89. Vorleben nicht bekannt. Beginn der Erkrankung Januar 89 nach Fall von einem Stuhl. Später noch 2 mal die Treppe heruntergefallen. Nachlass der Arbeitsfähigkeit. Unfähig die Worte zu finden, Anstossen beim Sprechen, unzusammenhängende Reden, Vibriren der Gesichtsmusculatur beim Sprechen. Stat. Zunge zittert, Pupillen eng, lichtstarr, Zittern in der Musculatur, Herabsetzung der motorischen Kraft, Analgesie, Steigerung der P. S. R., Patellarclonus; hochgradige Euphorie, blödes Geschwätz. 6. 6. Schenkelhalsfractur rechts, den 9. 9. wurde 
Patient nach dem Landeshospital Haina gebracht, woselbst er am 15. 9. 89 verstorben ist. Ueber die Todesursache ist mir nichts bekannt geworden.

B., geb. 13. Sept. 53, aufg. 20. Mai 87, gest. 8. Juni 87. Normale Entwickelung, kam im Geschäft nicht recht vorwärts. Oct. 86 wegen Schwäche aus dem Geschäft entlassen, es bestanden schon damals Sprachstörungen. Bald darauf, ängstlich, misstrauisch. Stat. Sprachstörung, gesteigerte P.S.R., sehr ängstlich; von 5. 6. ab Katheterismus, Nahrungsaufnahme ungenügend. 8. 6. Collaps. Exitus. Hirngewicht 1160. Haematoma Durae. Verfärbung der H. Str.

B., geb. 21. April 41, aufg. 21. Januar 96, gest. 28. Mai 96. Früher immer gesund, angeblich keine Syphilis, gesunde Kinder. Herbst 95, geschäftlicher Rücligang, psychisch verändert, bald darauf Grössenideen. Stat. PSR. gesteigert. Euphorie, Grössenideen, Demenz, stark herabgesetzte Merkfähigkeit. Seit April stärkere, motorische Erregung, schnelle Verblödung. 16. 5. Phlegmone am rechten Unterschenkel. 25. 5. Dämpfung LHU.-- Hirngewicht 1360. Dura schlotternd, geringes Atherom der Carotiden, starker Hydrops meningeus, Trübung der Häute. Atrophie im Stirn- und ScheiteIlappen. Hydrops ventriculorum, Ependymitis granulosa, Lobuläre Pneumonie.

B., geb. 3. Mai 61, aufg. 17. September 90, gest. 24. Januar 91. Normale Entwickelung, August 90, nachlässig im Geschäft, ruhelos, bald darauf erregt, zerstörungssüchtig, Grössenideen. Sta tus. Heiter erregt, verwirrt, unsinnige Grössenideen. R. P. $>$ L., beide reagiren. PSR. verstärlkt. Unsicherer Gang. Erregung besteht fort. 2. October erneute Untersuchung. PSR. rechts fehlt, links berabgesetzt. Romberg, Pupillenreaction träge. November ruhiger, deutliche Sprachstörungen, PSR. fehlen beiderseits, meist euphorisch, zeitweise zornig, haltlos, blöde. 7. Januar 91, vollkommen verwirrt, aphasisch, in den nächsten Tagen somnolent. Seit 21. Januar Katheterismus, 23. Januar Pneumonie. Gehirngewicht 1520. Oedem der weichen Häute. Keine makroskopisch wahrnehmbare Atrophie der Windungen. Im Lendentheil Verfärbung der HStr., grosse Mengen von Körnchenzellen. Pneumonia lobularis. Untersuchung nach Exner. Starker Schwund der Fasern der Rinde im Rectas, Fornicatus und Frontalis I, kein Schwund im Frontalis III, Centr. ant. und Occipitallappen.

L., geb. 23. December 27, aufg. 2. Mai 82, gest. 16. August 82. Anamnese mangelhaft. Von Kind auf still und unselbständig, allmäliger Beginn der Erkrankung, März 82. Grössenideen. „Bei der Aufnahme sah man ihm den Paralytiker schon ron weitem an." Status. Ptosis beiderseits, Strabismus divergens. Pupillen starr bei Lichteinfall, Convergenz und Accomodation. PSR. gesteigert, Romberg, unsicherer Gang, Euphorie, sinnlose Grössenideen, 31. August paralytischen Anfall. Plötzlicher Tod. Gehirngewicht 1330, Verfärbung in den SStr. and HStr. des Rüekenmarks. Trübung der weichen Häute, Hydrops meningeus et ventriculorum. Ependymgranulationen. Hirnhypertrophie, Atherom der Aorta, Emphysema pulmonum.

H., geb. 9. April 53, aufg. 5. Januar 00, gest. 18. Mai 00. Normale Entwicklung, nach eigener Angabe 74. Schanker, Ehe kinderlos. December 99. 
Beginn der Erkrankung, arbeitete nicht mehr, aufgeregt. Grössenideen. Status. Elendes Aussehen, linsengrosse Narbe am Sulc. coronarius, indolente Leistendrüsen, Cubitaldrüsen; fliehende Stirn, Circumferenz des Schädels $55 \mathrm{~cm}$. R. Facialis schlaff, Pupillen-Reaction träge, Sprachstörungen, Vibriren der Gesichtsmusculatur, spastisch atactischer Gang, Romberg, PSR. lebhaft, Analgesie, Euphorie, erregt, dement, heitere Erregung besteht fort, zwischen hindurch zornig dementes Gefasel mit blöden Grössenideen. Im März sehr erregt, Furunkulose, April ruhiger, sehr ablenkbar. Anfang Mai Decubitus mit Abscessbildung. 16. Mai Gonitis links. Exitus 18. Mai. Gehirngewicht 1330, Dura über Stirnbein schlotternd. Trübung und Oedem der weichen Häute über Stirn- und Scheitellappen. Hydrops ventriculorum, Ependymgranulation. Atrophie in den vorderen Parthien des Grosshirns. Im Anfangstheile der Aorta einige Verdickungen, an einer Stelle eine stecknadelkopfgrosse Verkaltung.

Die mikroskopische Untersuchung ergab einen Befund, der von dem bekannten Bilde nicht wesentlich abwich. Die weichen Häute des Rückenmarks waren mässig verdickt und enthielten eine abnorm grosse Zahl von eingelagerten Rundzellen. An den Wurzeln waren Veränderungen nicht wahrzunehmon. Die HStr. waren kaum als erkrankt zu bezeichnen, es waren jedoch die Septa etwas verbreitert, die Zahl der Neurogliakerne vermehrt, und eine Anzahl von Nervenfasern geschwollen. Dieser Process war dabei vollkommen diffus, irgend ein bestimmter, besonders stark erkrankter Abschnitt im Gebiete der HStr. liess sich nicht erkennen. Die aus den Burdach'schen Strängen in die HH. einstrahlenden Fasern waren intact. Ebenso war das Fasernetz in den Clarke'schen Säulen unverändert. Die PySStr. waren von einer stärkeren, im Uebrigen Besonderheiten nicht bietenden Degeneration befallen; ebenso war ein Schwund der Fasern in den Fürstner'schen Feldern wahrzunehmen. Im Uebrigen wäre noch zu erwähnen, dass die Gefässe des Rückenmarks vielfach eine Verdickung der Wandungen aufwiesen, von einer Endarteriitis war jedoch nichts za entdecken, es war diese Verdickung vor allem auf eine Wucherung' der Adventitia zurückzuführen.

Die weichen Hänte des Stammes wiesen dieselken Veränderungen wie die des Rüokenmarks auf, nur war hier die Vermehrung der Kerne noch grösser, und die Einlagerung von Rondzellen noch stärker. Desgleichen waren auch hier die Wandungen der Gefässe verdickt. Die basilaren grossen Gefässe wiesen dabei nur geringe Veränderungen auf und waren frei von stärkeren endarteriitischen oder atheromatösen Processen. Im IV. Ventrikel fand sich eine Ependymitis geringen Grades. Starke Glia-Wucherungen waren nur am Calamus scriptorius anzutreffen, sie reichten hier in Keilform weit in den Stamm hinein.

Vom Gehirn wurden zu mikroskopischen Untersuchung Frontal-Schnitte durch den rechten Stirn- und Hinterhauptslappen gelegt. Die weichen Häute waren in stärkerem Grade verdickt und enthielten in ihren Maschen eine grosse Menge von eingelagerten Rundzellen. Zudem fiel die grosse Zahl und auch die Weite und starke Anfüllung der in ihnen enthaltenen Blutgefässe auf. Diese Veränderungen waren sehr ausgesprochen im Stirnlappen, fehlten jedoch durchaus nicht vollkommen im Occipitallappen. Dieser liess im Uebrigen 
nennenswerthe Veränderungen nicht erkennen, höchstens war eine geringe Gliawacherung an der Oberfläche der Rinde wahrzunehmen. Im Stirnhirn fanden sich dagegen sehr wesentliche Veränderungen. Das Netz der Tangential-, der Supra- und Intraradiären Fasern war an den verschiedenen Stellen in allerdings verschiedener Stärke gelichtet, es fanden sich jedoch nirgends Parthien, in welchen es zu einem vollständigen Schwunde gelrommen war. Die Lagerung der Ganglienzellen in der bekannten Zeilenform war nicht weiter verändert. Es liessen sich aber bereits bei schwachen Vergrösserungen sowohl in der grauen als in der weissen Substanz eine übergrosse Zahl von Neurogliakernen nachweisen. Zu einer sehr intensiven Gliawucherung war es in der obersten Rindenschicht gekommen, hier sah man eine ausserordentliche grosse Menge von Gliafasern, Kernen, grösseren und kleineren Gliazellen. Die Gefässe des Gehirns waren gleichfalls in erheblichem Grade verändert; ihre Wände waren verdickt und wiesen eine abnorm grosse Zahl von Kernen auf, vielfach waren den adventitiellen Räumen Rundzellen eingelagert, oder fanden sich Infiltrationen von Rundzellen in der Umgebung der Gefässe. Sehr zahlreich waren in der Rinde auch neugebildete Gefäss-Schlingen und Sprossen anzutreffen.

In zwei anderen Fällen verlief die Erkrankung längere Zeit in der gewöhnlichen Weise, um dann plötzlich in einem Stadium schwerster Erregung zum Ende zu führen.

H. aus Cassel, geb. 18. September 36, aufg. 1. März 81, gest. 10. März 81. Normale Entwickelung, sexuelle Debauchen, 16-18 Jahre vor Aufnahme Schanker, Sublimatpillen, 3Jahre vor Aufnahme Iritis syphilitica, Schmierkur, in der letzten Zeit Bartfnne, seit fast einem Jahr aufgeregt, sehr gesprächig, "Anlage zum Grössenwahn", Februar 81 wegen Nervosität in Kaltwasserheilanstalt, Bäder, Abreibungen, später Schmierkur, 16 Packete à 2,5-40 gr. Rapide Verschlechterung, starke maniacalische Erregung. Status. Hochgradig erregt, verwirrt, hört Stimmen, nicht zu fixiren, voller Contusionen, Pupillen ungleich. PSR. fehlen. Andauernd widerstrebend, lässt sich keine Nahrung beibringen, sinnlos erregt, stürzt sich kopfüber aus dem Bett auf den Boden, ganz incohärente Aeusserungen. 8. März hinfällig, collabirtes Aussehen, 9. März vollkommene Trübung des Bewusstseins, 10. März Exitus. Pachymeningitis externa, Trübung und Verdickung der weichen Häute, Atrophie der vorderen Parthien des Hirns. Ventrikel kaum erweitert. Geringe Ependymwucherung, graue Verfärbung in den HStr. des Rückenmarks, daselust zahlreiche Körnohenzellen und Corpora amylacea, die anderen Stränge frej davon.

H., geb. 30. December 63, aufg. 5. November 97, gest. 3. Februar 98. Brachte es in der Realschule nur bis Quarta, obgleich er 17 Jahre alt wurde; wurde Goldarbeiter, musste aber beständig von seinem Vater unterstützt werden; heirathete ohne Wissen des Vaters ein übelbeleumundetes Frauenzimmer. Ist nach eigener Angabe inficirt gewesen und hat geschmiert. Seit Juli 97 ohne Stelle, machte allerlei Projecte, wurde aufgeregt. 28. October Grössenideen, schlaflos. Status. Asymmetrischer Schädel, fliehende Stirn, Schädel- 
Circumferenz 481/2. Pupillenreaction erhalten, Sprachstörung, Vibriren in der Gesichtsmuskulatur. PSR. gesteigert, Hypalgesie, atactiseher-Gang, Romberg. Narbe am inneren Präputialblatt, indolente Drüsen. Sehr gehobene Stimmung, lebhafte motorische Erregung, extravagante Grössenideen. 11. November etwas benommen, Zuckungen nicht beobachtet, erst am 15. Norember wieder klar, Hemiparese links, PSR. links sehr gesteigert, L. Dorsalclonus. Später meist euphorische Stimmung mit Ideenflucht und sinnlosen Grössenideen, kommt in Folge der Erregung schnell herunter, vorübergehend für kurze Zeit tief deprimirt, 25. Januar leicht benommen, Fieber, Phlegmone am linken Arm. 26. Januar triebartige Erregung. 27. Januar deliriumartiger Zustand, Diarrhoeen. 1. Februar vollkommen triebartige Erregung. RHU. Dämpfung. 3. Februar Exitus.

Gehirngewicht 940 . Stirnbein stark rerdickt $(6 \mathrm{~cm})$. Dura schlotternd. weiche Häute über Stirnhirn getrübt, Windungen sehr atrophiseh. Keine herdartigen Erlrankungen. Ependym leicht granulirt, Ventrikel nicht besonders erweitert. Lobuläre Pneumonie.

Leider war nur das Rückenmark zur mikroskopischen Untersuchung aufgehoben worden. Bereits makroskopisch liess sich nach erfolgter Härtung auf den Schnittflächen des Rückenmarks eine ganz leichte Verfärbung der HStr. und SSt. erkennen. Ebenso zeigten in den Weigert'schen Markscheidenpräparaten die HStr. und SSt. eine diffuse hellere Färbung, die jedoch nur wenig gegen die übrigen Gebiete der weissen Substanz abstach. Ausserdem erschienen die Spitzen der Seitenhörner auffallend hell und schmal. Mikroskiopisch fand sich eine ganz geringe diffuse Vermebrung der Glia in den Gebieten der HS. und PySSt. - Eine Differenz zwischen den beiden Seiten des Rückenmarkes war nicht zu erkennen. Speciell in den HStr. war diese Vermehrung der Glia sehr gering und so diffus, dass man von einer Erkranlrung der einzelnen in denselben enthaltenen Fasersystemen nicht recht sprechen kounte. Die HW. liessen die Degenerationserscheinungen nicht erkennen, ebenso war auch ein Ausfall der in die HH. einstrahlenden Fasern, oder ein Faserschwund innerhalb der Clarke'schen Säulen nicht wahrzunehmen. Dagegen waren die Seitenhörner an Fasern verarmt und auch eine ausgesprochene Lichtung der Fasern innerhalb der mittleren Partien der grauen Substanz vorhanden. So hoben sich die Clarke'schen Säulen mit ihrem dichten, wohlerhaltenen Fasernetz scharf gegen die benachbarte graue Substanz ab.

Einen überraschenden Befund ergab die Untersuchung der nach Marchibehandelten Präparate. Es fand sich in denselben eine sehr mächtige Ansammlung von schwarzgefärbten Schollen, in dem I. PySStr. und in dem r. PVStr., hier bis zu dem Brustmarke herabreichend. In den HStr. und in dem r. PyS. Str. war gleichfalls eine Ansammlung derartiger Schollen wahrzunehmen, dieselbe war jedoch sehr gering und kaum stärker als in den übrigen Gebieten der weissen Substanz (Figur 1).

Die nach der van Gieson'schen Methode gefärbten Schnitte liessen pathologische Veränderungen an den Häuten des Rückenmarks, sowie an den Gefässen nicht erkennen, speciell möge betont werden, dass endarteriitische 
Processe an den Gefässen nicht wahrzunehmen waren. In den HStr. erschienen die Septen ein wenig verdickt, vielleicht war anch die Anzahl der Gliakerne daselbst vermehrt; jedenfalls aber waren hier schwerere Veränderungen nicht wahrzunehmen. Dagegen liessen die SStr. und im Hals- und Brustmark aach der r. PyVSt. deutliche Veränderungen erkennen. In den beiden PySStr. waren die Septen in stärkerem Grade verbreitert, und die ZahI der Gliakerne erheblich vermehrt. Neben diesen den beiden SStr. gemeinsamen Veränderungen, wies der l. PSSt. und der $r$. PVS. noch gewisse besondere Veränderungen auf. Es war hier eine Anzahl mehr oder minder stark geschwellter oder im Zerfalle begriffener Axencylinder anzutreffen. Bei einer Reihe dieser erkrankten Nervenfasern liessen sich noch weitere, den degenerativen Vorgängen angehörige Processe nachweisen. Es fanden sich in ihrer Umgebung sehr protoplasmatische Neurogliazellen und vereinzelt auch ein Hineinwuchern dieser dann rundlich erscheinenden Zellen in das Gebiet der Nervenfaser. In dem $x$. SSt. waren derartige Processe gleichfalls, jedoch nur ganz vereinzelt, anzutreffen. Ich werde auf diese Beobachtungen später noch zurückzukommen haben.

Ich habe diesen Befund so eingehend wiedergegeben, da er den Beweis zu liefern geeignet ist, dass bei der Paralyse wenigstens unter Umständen eine Abhängigkeit der Rückenmarkserkrankung von krankkaften Processen im Gehirn vorhanden ist. Patient erlitt am 11. November einen paralytischen Anfall, von welchem eine linksseitige Parese zurückblieb. Am 3. Februar, also beinahe drei Monate später erlag er seiner Erkrankung. Leider war das Gehirn nicht aufgehoben worden, so dass es nicht möglich war, die mit der Marchi'schen Methode nachzuweisende Erkrankung des Rückenmarks bis nach dem Cortex hin zu verfolgen. Trotzdem erscheint es vollkommen ungezwungen, diese Rückenmarkserkrankung auf den krankhaften Process im Cortex, durch welchen seiner Zeit der Anfall ausgelöst, und die Parese hervorgerufen wurde, zurückzufübren, und von einer absteigenden Degeneration zu sprechen. Es würde sich dieser Fall also jenen Fällen anschliessen, in denen bereits der Nachweis dieses Zusammenhanges erbracht ist, wie z. B. den Fällen von Boedecker und Juliusburger ${ }^{1}$ ) und Starlin$\mathrm{ger}^{2}$ ). Letzterer weist wohl ganz mit Recht darauf hin, dass gerade die Marchi'sche Methode berufen zu sein scheint, auf diesem Gebiete Klarheit zu verschaffen. Man kann diese Veränderungen wohl auch mit anderen, vor Allem mit der van Gieson'schen Methode wahrnehmen, wenn man durch den Marchi-Befund auf dieselben aufmerksam geworden

1) Anatomische Befunde bei Dementia paralytica. Neurologischos Centralbl. 1897.

2) Beitrag zur pathologischen Anatomie der progress. Paralyse. Monatsschrift für Psych. und Neurol. Bd. VII. 
ist. Wir haben in diesen Veränderungen augenscheinlich frische Degenerationsprocesse vor uns, deren Studium speciell noch dadurch sehr erschwert wird, dass es sich nicht um eine Degeneration ganzer, compacter Bündel, wie man sie z. B. bei experimentellen Rückenmarksdurchschneiduagen studirt hat, handelt, sondern um einen Erkrankungsprocess, der immer nur eine Anzahl mehr zerstreuter Fasern erfasst. Diese ersten Stadien der Degeneration sind aber trotz einer Reihe ausgezeichneter Arbeiten, von denen ich hier nur die Homén'schen erwähnen möchte, noch lange nicht genügend bekannt. Grade die Veränderungen, die in dem vorliegenden Falle an den van Gieson'schen Präparaten zu constatiren waren, haben durchaus den Charakter frischer, noch relativ acuter Vorgänge, womit ja der Marchi-Befund gut übereinstimmen würde. Es kämen in dieser Beziehung in Betracht: die Schwellung: und der Zerfall der Axencylinder, die Einwanderung von Neurogliazellen in die Nervenfasern, Aufnahme von Resten von Nervenfasersubstanz in diese Zellen und schliesslich der Zerfall, resp. die Fortführung derartiger Zellen durch den Blutstrom. - Neben diesen frischen Veränderungen finden sich freilich, und zwar ziemlich gleichmässig in beiden PyB. chronische Processe: Verdickung der Septa, Vermehrung der Gliakerne, so dass sich also hier in einem bereits chronisch erkrankten Gebiete ein frischer Process entwickelt hätte, dessen Ausgang freilich schliesslich auch eine Sklerosirung sein dürfte.

Einen ganz wesentlich anderen Verlauf zeigten die letzten vier Fälle.

K., geb. 28. Juli 27, aufg. 13. März 78, gest. 27. März 78. Normale Entwickelung, im Wesentlichen immer gesund, 4 Wochen vor Aufnahme Erregung, Patient wurde schlaflos und lrrankhaft misstrauisch, vermutbete von allen Seiten geschädigt zu werden, schnelle Steigerung der Erregung. Status. Starke Erregung, Vibriren im Gesicht beim Sprechen, nähere Untersuchung nicht möglich, schimpft, schreit unaufhörlich, sinnlose Grössenideen, dazwischen ängstlich. 24. März Bronchialkatarrh, furibunde Erregung besteht fort. 26. März Temperatursteigerung, Dämpfung über dem linken Oberlappen, Rasselgeräusche; 27. März Gehirngewicht 1410. Pachymeningitis externa, Trübung und Infiltration der weichen Häute über den vorderen Theilen des Grosshirns. Schnittflächen des Gehirns mit Blutpunkten übersät, welche sich zu grossen Tropfen verstärken und confluiren. Plexus sehr blutreich; mässig viel Serum in den Ventrikeln; Ependymgranulationen im IV. Ventrikel.

v. G., geb. 14. September 53, anfg. 19. Mai 97, gest. 27. Mai 97. Keine erbliche Verarlagung, als Kind vorübergehend lungenleidend, sonst normal. entwickelt, günstige äussere Verhältnisse, im 16. Lebensjahre Gonorrhoe und Ulous molle. 95. Lungenspitzenkatarrh. Einige Monate vor Aufnahme reizbar, unnatürlich lustig. 20. April eigenartiger Anfall, soll damals nichts von 
sich gewusst haben, war nachher aufgeregt. 9. Mai Differenzen mit seinen Angehörigen einer Liebesgeschichte. wegen, darauf sehr aufgeregt, redete nachher viel „dummes Zeug". 15. Mai bei der Abreise aus seiner Heimath kurzer Anfall von Raserei. 16.-18. Mai in einer Wasserheilanstalt. Schnell sich steigernde hochgradige Erregung. Status. Ausserordentlich starke Erregung, schreit, stösst unarticulirte Laute aus, zerreisst seine Kleider, wirft sich auf den Boden, wälzt sich umher, versucht sich auf den Kopf za stellen, rauft sich den Bart, zerrt sich an den Genitalien. Zeitweise jammert er vor sich hin, oder rennt mit dem Ausdruck ängstlicher Verzwoiflung umher. Nach einigen Stunden etwas ruhiger, aber ganz unorientirt und unklar; vorübergehend weinerlich. Frühgealterter Mann, der ganze Körper ist mit blauen und braunen Flecken bedeckt. P. 132. Linker Facialis schlaff. R. Pupille stecknadelkopfgross, linke über mittelweit. Beide Pupillen lichtstarr, feinschlägiger Tremor der Finger, Zunge zittert, starkes Silbenstolpern. PSR. beiderseits gesteigert, links schwacher Patellarclonus. Urin ziegelroth, sehr trübe, sauer. Gewicht 1025. Die bochgradige Erregung bestand mit geringen Unterbrechungen die nächsten Tage hindurch fort. Patient war laum einmal für Momente zu fixiren. rannte im Isolirzimmer umber, bearbeitete seinen Körper mit seinen Fäusten. Viclfach zeigte er alle Zeichen der Angst, jammerte und schrie, dass man ihn vergiften wolle. Nur vorübergehend war es möglich ihn durch verlängerte Bäder ein wenig zu beruhigen. Vom 23. Mai ab zeigte er ein vollkommen triebartiges Verhalten, er wüthete blindlings gegen sich und seine Umgebung, dabei war er ängstlich verwirrt, sein Bewusstsein ganz getrübt, so dass es vollirommen unmöglich war, mit ihm irgend wie in Connex zu treten. Feste Nahrungsmittel nahm er nicht, zu sich, sondern spuckte sie ohne weiteres wieder aus, dagegen gelang es, ihm immer noch flüssige Nahrungsmittel beizubringen. Er hatte sich am 23. den Nagel der rechten Zehe vollkommen herausgerissen und arbeitete sich auch in den nächsten Tagen andauernd an dieser Zehe herum. Es entwickelte sich von dieser Zehe ausgehend ein schnell sich ausbreitender phlegmonöser Process, der alsbald auf den Cnterschenkel übergriff. Am 25. Mai stellte sich Temperatursteigerung ein, zugleich wurde der Puls anch frequenter (140) weich und unregelmässig. Am 26. Mai trat Benommenheit ein, beginnende Infiltration des rechten Unterlappens. Am 27. Mai war Patient vollständig somnolent, Abends 61/2 Uhr trat der Exitus ein.

Autopsie 28. Mai Vormittags: Gehirngewicht 1170. Dura über dem Stirnh irn schlotternd, pachymeningitische Auflagerungen, weiche Häute ödematös, zum Theil sulzig getrübt. In den vorderen Partien des. Hirns starke Verschmälerung der Gyri bei Verbreiterung der Sulci. Keine Erweiterung der Seitenventrikel, daselbst keine Ependymgranulationen; Ependym des IV. Ventrikels in der Gegend des Calamus scriptorius granulirt. Auf den Schnitten sehr zahlreiche Blutpunlte. Im Rückenmark Verfärbung der H. und SStr. Im Uebrigen ergab die Autopsie folgenden Befund: Kleine Ulcerationen an den Stimmbändern; Zungengrund glatt; diffuse atheromatöse Entartung der Aorta thoracica. Klappenapparat des Herzens intact, Coronararterien frei von Atherom. Verkäste Herde in den Lungenspitzen, Pneumonia lobularis. 
Untersuchung nach Exner: Gyr. rectus sehr starker Faserschwund, beinahe noch stärker im Gyr. frontalis I. Im Gyr. centralis ant. mässiger Faserschwund. Im Oecipitalis sehr dichtes Fasernetz.

Leider war seinerzeit zur mikroskopischen Untersuchung nur das Rückenmark aufgehoben worden. Die weichen Häute desselben waren etwas verdickt und bestanden aus derbem Bindegewebe. Von einer nennenswerthen Vermehrung der Kerne war nichts nachzuweisen, vor allem fanden sich keine grösseren Ansammlungen von Kernen in der Umgebung der Gefässe. Auch die Gefässe der weichen Häute wiesen pathologische Processe nicht auf, höchstens wäre die Wandung einer Reihe der kleineren und mittleren Arterien als verdickt zu bezeichnen; diese Verdickung betraf dabei ausschliesslich die Adventitia und Media. Ein auffallender Kernreichthum war auch an diesen Stellen nicht wahrzunehmen. Endarteriitische Processe waren nirgends aufzufinden.

Auf den nach van Gieson behandelten Schnitten fiel die grosse Anzahl der Gefässe auf. Diese Erscheinung beruhte zum grössten Theile darauf, dass die Gefässe sämmtlich mit Blut sehr stark gefüllt waren und somit viel mehr als sonst hervortraten. Zum Theil machten sich wohl anch die Gefässe durch die Verdickung ihrer Wandungen mehr als sonst bemerkbar. In der grauen Substanz und auch vereinzelt in dor weissen fanden sich kleine frische Blutungen vor, von irgend welchen reactiven Veränderungen in der Umgebung derselben war nichts zu erkennen. Ausserdem liess sich in dem Gebiete der PySSt. und der HSt. eine allerdings nur sehr geringe Vermebrung der Glia wahrnehmen. In den caudalen Theilen des Rückenmarks erstreckte sich diese leichte Gliawucherung auf die mittleren Parthien der HSt., so dass unter anderem die Wurzeleintrittszonen frei blieben. In dem oberen Brust- und dem Hals-Theile fand sich dieser Process in dem Gebiete der Goll'schen Stränge. Wie gering diese Vermehrung der Glia war, zeigten sehr deutlich die Weigertschen Markscheiden-Präparate, in welchen sich die erkrankten Parthien für das blosse Auge in nur grade noch erkennbarer Weise von den übrigen Gebieten der weissen Substanz abhoben. Bei der Durchmusterung der Giesonschen Präparate liess sich in den erkrankten Parthien eine Vermehrung der Kerne und eine grössere Zahl jener protoplasmareichen Neurogliazellen auffinden. Ueberhaupt zeigte die Neuroglia auch in den verbreiterten Septen nicht den für ältere Sklerosen charakteristischen Filz von derben, starren Gliafasern. Hin und wieder waren geschwollene Axencylinder und auch Körnchenzellen ähnliche Gebilde in den Räumen untergegangener resp. untergehender Nervenfasern nachzuweisen.

$\mathrm{Zu}$ erwähnen wäre noch, dass vereinzelt in allen Theilen des Rückenmarks, sehr zahlreich aber in deni Gebiete der HSt. des Rückenmarks Corpora amylacea anzutreffen waren. An den hinteren und vorderen Wurzeln waren pathologische Processe nicht wahrzunehmen, ebenso war das Fasernetz innerhalb der Clarke'schen Särlen und auch innerhalb der übrigen grauen Substanz normal, höchstens könnten die Fasernetze der Fürstrier'schen Felder als leicht gelichtet bezeichnet werden.

H., Postbeamter, geb. den 12. October 61, aufg. den 27. December 99, 
gest. den 23. Januar 1900. Patient ist hereditär nicht belastet. L'eber sein Vorleben ist im ganzen wenig bekannt. Er besuchte die Elementarschule, war 9 Jahre lang Soldat. Nach seiner eigenen Angabe ist er inficirt gewesen und hat eine Schmierkur durchgemacht. Seit dem 20. December 92 ist er verbeirathet, 2 Kinder im Alter von 5 und 3 Jahren. Im Herbste 99 wurde er apathisch und unfähig zur Arbeit, im November 99 wurde er Unregelmässigkeiten in seinem Dienste halber beurlaubt, im December erschien er verstimmt und leicht vergesslich. Fnde December (23. December) wurde er erregt, sprach viel und laut, äusserte Grössenideen. Zugleich gab er sich Alcoholexcessen hin, nach welchen sich seine Erregung sehr schnell steigerte, er wurde schliesslich ausgesprochen tobsüchtig und aggressiv gegen seine Familie, sodass prolizeiliche Hülfe requirirt werden musste.

Bei der Aufnahme war Patient in hohem Grade erregt und widerstrebend, er schlug blindwüthend auf seine Umgebung ein. Nur ganz vorübergehend war er insoweit zu beruhigen und zu fixiren, dass von ihm einzelne Angaben za erhalten waren. Im Uebrigen schimpfte er in wüster Weise, oder brachte auch in wirrem Durcheinander Grössenideen vor. Eine genaue Untersuchung war unmöglich, constatirt werden konnte nur, dass der linke Facialis paretisch war, und die Pupillen ungleich und lichtstarr waren. Ausserdem war eine ausgesprochene Sprachstörung vorhanden. Seiner hochgradigen Erregung wegen musste er isolirt werden. Am nächsten Tage war er vorübergehend etwas ruhiger. - Ueber seinen Körper zerstrent fanden sich eine Reihe von Contusionen, die er sich selbst bei seinem Toben beigebracht hatte. Eine Wiederholung der Untersuchung bestätigte den Befund, ausserdem fand sich eine erhebliche Herabsetzung derSchmerzempfindlichkeit, die P.S.R. waren vorhanden. Nahrungsaufnahme nicht genügend. In der nächsten Zeit war Patient ganz ausserordentlieh erregt, sang, lärmte, tobte in dem Isolirraum umher, schlug auf jeden ein, der in seine Nähe kam, brachte in zusammenhangloser Weise blöde Grössenideen vor, war garnicht zu fixiren. Die Sprachstörungen nahmen schnell zu; die Nahrungsaufnahme war zufriedenstellend, wenngleich Patient viel mit den Speisen umherschmierte. Am 16. Januar 1900 fanden sich auf dem rechten Unterschenkel eine Reihe von Excoriationen, von selbstbeigebrachten Kratzwunden herrührend, vor, deren Grund und Umgebang entzündliche Erscheinungen aufwies. Dieselben waren augenscheinlich darauf zurückzuführen, dass Patient seine Unterschenkel immer wieder mit den Nägeln bearbeitete und Speichel and Schmutz in die Wunden hineinschmierte. Alle Verbände wurden von dem Patienten sofort wieder abgerissen. Bereits am Abend war die Temperatur auf 41 gestiegen. Am 20. Januar wurde durch eine Incision in der Nähe der Erosionen eine stinkende eitrige Flüssigkeit entleert. Trotzdem blieb das Fieber über 40. Zugleich wurde Patient benommen. P. 120 irregulärt von geringer Fülle und Spannung. Campferinjectionen. Am nächsten Tage hatte sich eine ausgedehnte Nekrose am rechten Lnterschenliel entwickelt, beim Abtragen der necrotischen Hautparthien entleerte sich stinkender Eiter. Patient wurde somnolent und verfiel im Laufe dieses und des nächsten Tages rapid. Exitus 23. Januar, Morgens 6 Uhr. 
Autopsie. 23. Januar. 9 Stunden post mortem. Schädeldach ausserordentlich schwer, starke Verdickung der Knochen bei Verschmälerung der Diploë. Die Dura umgiebt das Stirnhirn als schlotternder Sack, über dem Parietal- und Hinterhauptslappen erscheint sie dagegen stark gespannt. Auf der Innenfläche der Dura finden sich pachymeningitische Auflagerungen mit einer grossen Menge punktförmiger bis erbsengrosser Bluteinlagerungen. Stärkere pachymeningitische Auflagerungen sind in den mittleren und ror allem in den vorderen Schädelgruben anzutreffen. Hirngewicht 1350. Starker Hydrops meningeus. Die weichen Häute erscheinen getrübt, zum Theil sulzig, an einzëlnen Stellen zeigen sich blutige Suffusionen. Die weichen Hänte der Hinterhauptslappen sind von diesen Veränderungen frei, sie beben sich scharf gegen die vorderen Parthien ab. Sehr ausgesprochen ist die sulzige Trübung der weichen Häute über den vorderen Parthien der Unterfläche des Gehirns. Die grossen Gefässe an der Basis cerebri sind zart, auch sonst ist von einer Atheromatose der Gefässe nichts wahrzunehmen. Die Configuration und Anordnung der Windungen lässt Abnormitäten nicht entdecken, die Windungen des Stirnhirns sind deutlich verschmälert. Ependymgranulationen in den Seiten- und am Boden des IV. Ventrikels. Weiche Consistenz des Gehirns; auf den nach der Fixirung in Formol angelegten Schnitten sieht man ganz ausserordentlich viele Quer- und auch Längsschnitte von Gefässen; die Rinde im Gebiete des Stirnhirns ist deutlich verschmälert.

Das Rückenmark zeigt eine ganz auffallend weiche Consistenz. Die Gefässe sind sehr stark gefüllt. Im unteren Brustmark findet sich eine vollkommen erweichto Stolle. Auf Querschnitten des Rückenmarks erscheinen die HStr. nicht rein weiss.

Von den übrigen Ergebnissen der Section möge hier nur nachstehendes erwähnt werden. Am rechten Unterschenkel findet sich ein ausgedehnter Substanzverlust und eine eitrige Infiltration ress. Einschmelzung. Herzmuskulatur sehr schlaff. Intima der Aorta im Bulbus rauh und uneben, ohne Verkalkungen, im weiteron Verlaufe der Aorta sind pathologische Veränderungen der Intima nicht wahrzunehmen. In der rechten Niere ejn hanflkorngrosser Eiterherd, die Rinde der Nieren erscheint getrübt.

\section{Mikroskopische Untersuchng.}

Die weichen Häute des Rückenmarks sind etwas verdickt, weisen einen abnormen Kernreichthum und eine mässige infiltration mit Rundzellen auf. Die Infiltration jst diffus und nicht an einzelnen Stellen wio z. B. in der Umgebung der Gefässe besonders stark. Die Gefässe der weichen Häute haben vielfach verdickte Wandungen, an einzelnen Gefässen und zwar an Gefässen, welche jn der Nähe der hinteren Wurzeln liegen, findet sich eine stärkere endarteriitische Wucherung, bestehend aus derberen welligen Bindegewebszügen, welchen eine Anzahl von Kernen eingelagert ist. Hin und wieder trifft man in den weichen Häuten einzelne rundliche, concentriseh geschichtete Körperchen, die sich mit Hämatoxylin dunkelroth violett färbten und die Grösse der Corpora amylacea um ein vielfaches überragten. Mit Lugol'scher Lösung färbten 
sich dieselben duntrelbraun, bei Zusatz von Salzsäure wurden sie nicht aufgelöst. Grade in ihrer Umgebung sah man einzelne kleinere Gefässe, in welchen die Intima stark gewuchert war, sodass es zu einem Verschluss des Gefässes gekommen war. Die. Wandungen dieser Gefässe waren dabei derart verändert, dass sie eigenartig glänzend erschienen und ihre normale Structur verwischt war, die in ihnen gelegenen Kerne nahmen zugleich nicht mehr in der gewohnten Weise die Farbe an.

Weigert'sche Markscheidenpräparate liessen in den HStr. Degenerationsvorgänge erkennen. Ueber die Ausbreitung derselben über die einzelnen Gebiete der HStr. dürften die beigegebenen Skizzen in genügender Weise Auskunft geben (Fig. 2). Auch in den am stärksten degenerirten Zonen waren immer noch eine grössere Anzahl von wohlerhaltenen Nerrenfasarn aufzufinden. Ebenso waren auch die HW. erkrankt, und zwar war der Degenerationsprocess in den untersten Wurzeln am ausgesprochensten, um nach oben hin abzunehmen und im Halsmark ganz zu schwinden. Es handelt sich dabei nirgends um eine vollkommene Degeneration der Wurzeln, auch da, wo der degenerative Process ạm stärksten war, war in den Wurzeln immer noch eine grössere Anzahl intacter Nervenfasern vorhanden.

In entsprechender Weise war es auch, wenigstens in den unteren Abschnitten des Rückenmarks zu einem Ausfall der in die HH. einstrahlenden Fasern gekommen. Diø Clarke'schen Säulon liessen einen deutlichen Schwund ihres Fasernetzes erkennen, und ebenso wiesen auch die Seitenhörner eine Lichtung ihros Fasernetzes auf. In den PySSt. war in diesen Präparaten eine Degeneration nicht wahrzunehmen.

Abgesehen von diesen Veränderungen fielen auf den Querschnitten kieine Herde auf, in welchen die Axencylinder colossal geschwollen waren bei Schwund oder vollkommenem Zerfall der Markscheide. Auf diesen Befund werde ich nochmals zu sprechen kommen.

Auch in den van Gieson'schen Präparaten wiesen die Veränderungen in den HStr. irgendwelche Besonderheiten nicht auf, es präsentirte sich der Degenerationsprocess ganz in der Weise, wie wir ihm oftgenug bei Paralytikern zu sehen bekommen. Jedenfalls handelt es sich hier nicht um schr alte Processe, es sprach hiergegen einmal, dass auch in den am stärksten erkrankten Partien immer noch eine Anzahl von Nervenfasern intact war, und dass es nicht zu der Bildung jenes den älteren sklerosirenden Processen eigenen, diohten Filzwerkes ron Neurogliafasern gekommen war. Andererseits konnte man aber auch nicht von einem ganz acuten Process sprechen. Es waren in den degenerirten Partien wohl einzelne geschwellte Axencylinder vorbanden, nirgends aber fand sich əine grössere Anzahl dieser stark geschwellten Axencylinder vor, nirgends traf man auf grössere Mengen zerfallender Axencylinder und Myelinscheiden; ebensowenig war eine grössere Zahl jener protoplasmareichen, grosskernigen Neurogliazellen vorhanden, desgleichen sah man auch nur ganz vereinzelt jenes Eindringen von Zellen in die Räume der Nervenfasern.

Ebenso liessen auch die hinteren Wurzeln nichts von dem gewöhnlichen Degenerationsprocesse abweichendes erkennen. Zu erwähnen wäre nur noch, 
dass sich in den HW. auffallend viele weite Gefässe mit zum Theile sehr erbeblich verdickten Wandungen vorfanden.

Während in den Weigert'schen Präparaten von einer Degeneration in den SStr. nichts wahrzunehmen war, zeigten die Gieson-Präparate, dass auch diese nicht vollkommen frei von Veränderungen waren. Es fand sich hier eine geringe Vermehrung des Stützgewebes; ausserdem liess sich eine allerdings beschränkte Zahl van geschwollenen resp. zerfallenden Axencylindern nachweisen. Ganz vereinzelt waren derartig erkrankte Axencylinder übrigens anch in den übrigen Gebieten der weissen Substanz aufzufinden.

Im Uebrigen zejgten die Gefässe des Rückenmarks fast sämmtlich eine Verdickung der Wandungen. Ausserdem konnte auch bei den zur Anwendung gezogenen Methoden (Formolhärtung, van Gieson) constatirt werden, dass eine Anzahl von Ganglienzellen sklerosirt waren. Es waren von dieser Veränderung weniger die multipolaren Vorderhornzellen betroffen, als die in den mittleren Theilen der grauen Substanz gelegenen Strangzellen. Hin und wieder fanden sich, allerdings fast ausschliesslich in der grauen Substanz, kleine frische Blutungen vor. Auffallend war auch ganz besonders im Gebiete der HSt. die ausserordentlich grosse Zahl der Corpora amylacea.

Ausser diesen mehr allgemeinen Veränderungen waren, worauf bereits hingewiesen ist, noch herdartige Krankheitsprocesse vorhanden. Es fanden sich in den einzelnen Höhen in wechselnder Zahl eine Anzahl kleinerer Krankheitsherde. Dieselben lagen meistens im Gebiete der Seitenstränge, und zwar ein wenig von der Peripherie entfernt, sodass sie von dieser immer noch durch eine schmale Zone normaler Substanz getrennt waren. Seltener waren dieselben in den mehr centralen Partien des Markes anzutreffen. Bei der Schilderung dieserHerde kann ich mich ganz kurz fassen, da ich bereits einmal genau den gleichen Befund erheben konnte, so dass ich mich auf meine damalige sehr eingehende Beschreibung beziehen kann '). Es handelt sich - in Kürze gesagt - um kleine Herde von 10 bis höchstens 15-20 mehr oder minder stark geschwellten Axencylindern, die zum Theil Zeichen des Zerfalls darbieten. In der Umgebung und auch wohl im Innern dieser Herde zeigt die Neuroglia eine geringo Wucherung, man findet hier vielfach jene grösseren protoplasmareichen Gliazellen und auch jene eigenthümliche Anlagerung von Gliazellen an die erkrankten Axencylinder. Von einer Infiltration von Rundzellen ist übrigens in der Umgebung dieser Herde nichts wahrzunehmen.

Schnitte aus der bei der makroskopischen Beschreibung erwähnten erweichten Partie des Rückenmarkes deckten eine weitgehende Zerstörung der Configuration des Querschnittbildes auf. Irgend welche Besonderheiten hat im Uebrigen der Befund nicht. Es handelte sich trotz der frühen Section um eine postmortale Erweichung.

Die Degeneration der HStr. des Rückenmarks liess sich bis in den Stamm hinein verfolgen, war jedoch sehr wenig ausgedehnt und nahm eine schmale

1) Uebex einen Fall syphilitischer Erkrankung des Centralnervensystems. Diesés Archiv Bd. 32. 
Zone zwischen den Goll'schen und Burdach'schen Kernen ein. Der Boden des IV. Ventrikels war von zahlreichen Ependymgranulationen bedeckt, auffallend war an denselben, dass sie sehr viele Kerne enthielten; nur in einzelnen sah man jene dichten, mehr kernarmen Gliazüge, wie man sie in älteren Wucherungen anzutreffen pflegt. Die weichen Häute des Stammes zeigten dasselbe Verhalten wie die des Rückenmarks, auch sie waren verdickt und von einer mässigen Zahl van Rundzellen durchsetzt. Ebenso erschien hier sowohl als auf dem Querschnitte des Stammes eine grössere ZahI der Gefässe auffallend dickwandig. Es möge jedoch speciell betont werden, dass sich stärkere endarteriitische Veränderungen resp. Processe atheromatöser Art nicht vorfanden, auch nicht an den grösseren basalen Gefässen, ja diese gerado zejgten zum grössten Theile absolut normale Verhältnisse. In Uebrigen bot der Hirnstamm keine Besonderheiten dar.

Von dem Gehirn wurden zur mikroskopischen Untersuchung Frontalschnitte aus dem rechten Stirn- und Hinterhauptslappen angelegt. Bei der Beurtheilung der Weigertpräparate möchte ich mir, wenigstens soweit negativo Resultate in Frage kommen, eine gewisse Vorsicht auferlegen, da es sich um Präparate aus Formol handelte, die doch wohl nicht alle Garantien bieten. Jedenfalls waren aber auch im Stirnlappen noch eine ganze Reihe von Tangential- -supra- und intra-radiären Fasern erhalten. Die Dichte dieses Fasernetzes schwankte alllerdings in den einzelnen Partien der doch schon immer umfangreichen Schnitte recht erheblich.

Der schon makroskopisch wahrnehmbaren Trübung der weichen Hänte entsprechend fand man im mikroskopischen Bilde eine im Gebiete des Stirnlappens recht beträchtliche Verdickung der Häute und eine ziemlich starkeInfiltration mit Rundzellen. Dabei wiesen die weichen Häute eine auffallend grosse Zahl von zum Theil stark erweiterten Gefäsșen auf. Diese Gefässe batten vielfach verdickte Wandungen und zeigten in denselben einen abnormen Kernreichthum. Nirgends fanden sich, was bier noch besonders betont werden möge, Veränderungen, die auf einen syphilitischen Process hinweisen könnten. Ueber dem Hinterhauptslappen war die Verdickung und Zellinfiltration der weichen Häute sehr viel geringer, doch waren die Häute durchaus nicht vollkommen frei von pathologischen Processen.

Die Schnitte aus dem Occipitallappen wiesen im übrigen normale Verhältnisse auf, nur an einzelnen Stellen fand sich eine geringe Wucherung der Glia in der obersten Rindenschicht.

In dem Stirnhirn waren dagegen recht starke Veränderungen anzutreffen, und zwar Veränderungen, wie sie dem Befunde bei der Dementia paralytica eigen sind. Schon bei schwächeren Vergrösserungen fiel die ausserordentlich grosse Menge der Gefässe auf, die sich noch besonders dadurch bemerlibar machten, dass sie im Allgemeinen mit Blut stark angefüllt waren und in ihren Wandungen resp. in ihrer Umgebung eine abnorm grosse Zahl von Kernen aufwiesen. Ebenso war die Zahl der Neurogliakerne besonders in der obersten Rindenschicht vermehrt.

Bei mittleren und stärkeren Vergrösserungen konnte man diesen Befund 
bestätigen und constatiren, dass die Wucherung der Neuroglia besonders in der obersten Rindenschicht einen erheblichen Grad erreicht hatte, dabei zeigten auf diesen grossen Schnitten die einzelnen Partien eine nicht unerhebliche Verschiedenheit in der Stärke des Processes. An den an stärksten afficirten Stellen sah man ein dichtes Netz von Gliafasern mit angelagerten Kernen. Wie immer war dieses Netz am dichtesten unter der Pia; ausserdem war diese Wucherung besonders stark in der Umgebung der Gefässe grösseren und kleineren Calibers, hier konnte man das bekannte Bild des Zusammenhanges der Gliafasern mit den Gefässwandungen wiederfinden. Ausserdem liess sich eine sehr starke Neubildung von Gefässen durch Sprossen- und Schlingenbildung nachweisen.

R., Regierungsassessor, geb. 13. September 1861, aufg. den 8. Juli 1896, gest. 17. Juli 1896. Patient ist erblich für Erkrankungen des Centralnervensystems nicht veranlagt. Er wuchs unter sehr günstigen Verhältnissen auf und entwickelte sich in normaler Weise. Bei einer guten intellectuellen Begabung fiel es ihm leicht, seine Examina zu absol viren, er lebtein geregelten Verhältnissen und warirgend welchen schädjgenden Einflüssen nicht ausgesetzt. Im Jahre $1883 \mathrm{zog}$ er sich eine specifische Infection zu. Eine energische Behandlung fand damals nicht satt. Späterhin sind mehrere Recidive aufgetreten, die sich angeblich unter Jodkaligebranch zurïckgebildet haben. April 1896 stellten sich angeblich. ganz acut Erscheirungen eines Rückenmarksleidens ein, das als Tabes dorsalis gedeutet wurde. Pat. war eines Morgens zum Gehen vollkommen unfähig. Es wurde sofort eine Schmierkur eingeleitet und $15 \times 5=75 \mathrm{~g}$ verschmiert. Es folgte derselben Anfang Mai eine zweite Bade- und Trinkkur in Tölz, woselbst auch eine woitere Schmierkur von $35 \times 4=140 \mathrm{~g}$ durchgeführt wurde. Die ersten Erscheinungen einer psychischen Alteration wurden bei dem Patienten, der sehr gut beobachtêt wurde und bis dahin geistig vollkommen intact ersehienen war, am 24. Juni 1896 wahrgenommen. Fs fiel damals der Umgebung des Patienten dessen erhebliche Gedächtnissschwäche auf. Am 26. Juni trat, während sich Patient mitten in einer Unterhaltung befand, ein einer tiefen Ohnmacht ähnlicher Anfall von Bewusstlosigkeit von $3 / 4$ stündiger Dauer ein. Es sollen damals auoh Zucirungen in den Händen beobachtet sein; nachträglich wurde noch eine ron einem Biss herrührende Wunde am rechten Rande der Zunge aufgefunden. Am 28. Juni klagte Patient über Geruchsempfindungen und zwar über einen unerträglichen Geruch von Linden- und Jasminblüten, er äusserte auch, dass er fortwährend Hundebellen und Hähnekrähen höre. Am 2. Juli wurden Blutungen in die Conjunctivae bulborum wahrgenommen. Zudem wurde constatirt, dass Patient die Personen verwechselte und sich in den Häusern verlief. Am 5. Juli Abends erklärte er in aufgeregter Weise in einem Bierlokale alle Anwesenden mit Ausaahme eines ihm unbekannten Herrn für verrückt. In den nächsten Tagen trat eine ausserordentlich schnelle Steigerung der Erregung ein. Patient fand nirgends Ruhe, redete fast andauernd, bauschte alle unwesentlichen Dinge in ungeheuerlicher Weise auf und sprach vielfach in verwirrter Weise. Schon vor selner Aufnahme in die hiesige Anstalt wurden nachstehende somatischen Symptome constatirt: Fehlen der P.S.R., Romberg, 
geringe Sensibilitätsstörungen, L.P. weiter als R. Beide Pupillen auf Lichteinfall reagirend. R. träger als $\mathrm{I}$.

Bei seiner Aufnahme war Patient in hohem Grade erregt, lief andauernd. im Zimmer umber, sprach in confuser Weise, erklärte seine Ueberführung nach der Anstalt für einen schlechten Scherz seiner Freunde, renommirte in schwächlicher. Weise mit seiner Muskelkraft. In der Nacht steigerte sich die Erregung zu ausgesprochener Tobsucht, Am. nächsten Morgen wurde er nach einem Bade etwas ruhiger, sodass er wenigstens vorübergehend zu fixiren war. Ers erkannte den Arzt wieder, wusste, wo er sich befand, glaubte aber bereits mehrere Tage lang hier zu sein. Einzelne Speisen wies er zurück mit der Bemerkung, dass sie vergiftet seien.

Status praesens. Mittelgrosser, gut genährter, kräftiger Mann. Ueber den Körper zerstreut finden sich eine Anzahl blutunterlaufener Stellen; an den Conjunctiven sind Ecohymosen und Blutunterlaufungen wahrzunehmen. L.P. weiter als R., R. P. reagirt auf Lichteinfall träger als die linke. Der linke Facialis sohwächer innervirt als der rechte. Die mässig belegte Zunge wird grade hervorgestreckt, sie zittert dabei sehr lebhaft. Die P.S.R. fehlen vollkommen. Ebenso fehlt der Achillessehnenreflex. Die Plantarreflexe sind sehr schwach; Cremaster und Bauchdeckenreflex sind nur angedeutet. Ulnarissymptom. Hochgradige Ataxie, Patient schleudert die Beine, taumelt vielfach, Stehen bei Augen- und Fussschlass ganz unmöglich. Die motorische Kraft der Beine erscheint herabgesetzt, während der Händedruck beiderseits sebr kräftig ist. Deatliche Hypalgesie an den unteren Extremitäten. Brust und Bauchorgane ohne pathologischen Befund. Der Urin giebt eine schwache Acetonreaction und bei der Eiweissreaction Opalescenz.

Auch während der Untersuchung war Patient andauernd erregt und sprach beinahe fortwährend in verwirter Weise. Er behauptete, bereits 4 Tage in der Anstalt zu sein, rühmte die Erfolge der Tölzer Kur, pries seine Muskeln aus Elfenbein, wollte sofort in seinen Dienst.

Des Abends wurde er wieder in stärkerem Maasse erregt, erkannte seine Umgebung nicht mehr, schlug blindlings anf alle Personen ein, trat um sich, stiess in brüllender Weise unarticulirte Laute aus. Er war dabei in Schweiss gebadet, sein Gesicht tief geröthet. Die motorische Unruhe machte sich anch in einem starken Grimmassiren und allerlei Verrenkungen seines Körpers Luft.

Diese hochgradige Erregung hielt in den nächsten Tagen, wenn auch in wechselnder Stärke an. Am 11. Juli stellte sich eine ausgesprochene Trübung des Bewrasstseins ein, er erkannte die Aerzte nicht mehr und war nicht mehr zu fixiren. Die triebartige Erregung steigerte sich zu einem vollkommen furibunden Verhalten.

Die Nahrungsaufnahme, welche in den ersten Tagen des Anstaltsaufenthaltes noch genügend gewesen war, wurde ungenügend; Patient nahm beinahe nur Flüssigkeiten zu sich und liess auch diese oftmals wieder aus dem Munde herauslaufen. Patient verfiel dabei zusehends, der Puls wurde klein und leicht unterdrückbar, beschleunigt, 100. Patient konnte sich kaum auf den Füssen halten, schlug aber trotzdem fast andauernd mit Händen und Füssen um sich. 
Der Urin zeigte eine ausgesprochene Eiweissreaction. Bei seinem Toben hatte sich Patient eine ganze Reihe von Verletzungen zugezogen. Am 14. Juli wurde Patient vorübergehend klarer, sodass er wenigstens zeitweiss zu fixiren war. Er klagte über Schmerzen, verlangte nach seinem Arzte (Dr. W. in C.), erklärte, nicht zu wissen, wie er hierher gekommen sei, und beschwerte sich darüber, dass ihm seine Freiheit geommen sei.

Am folgenden Tage war er sehr matt, der Puls schwanikte zwischen 100 und 110, war klein und weich. Psychisch war Patient jedoch noch freier als am Tage vorher; ex begrüsste den Arzt frendlich, erkundigte sich wieder, wie er hierher gekommen sei, klagte darüber, dass hier alles voller Bilder sei, die ihn so ängstigten. Von seiner furchtbaren Erregung wusste er nichts. Mittags hatte er einen schweren Schwächezustand, von dem er sich erst nach mehrfachen Gaben von Campher erbolte. Die Nahrungsaufnahme war etwas besser, vor allem nahm Pat. auch stärkere Alcoholica.

Am 16. Juli stellte sich eine erhebliche Steigerung der Temperatur ein, 39,0. Der Puls wurde unregelmässig und sehr klein, 120. Ueber beiden Trochanteren hatte sich Gangrän der Haut ausgebildet, und auch über dem ganzen Gesäss war die Haut dunkelroth verfärbt und derb infiltrirt. Die Athmung war dyspnoeisch, dieLippen borkig, die Zunge trocken, von fuliginösem Belage bedeckt. Patient musste des Abends catheterisirt werden, der Urin enthielt reichlich Eiweiss. Patient war benommen.

Im Laufe des nächsten Tages nahm die Gargrän schnell an Umfang zu und ergriff auch die Haut über den Ellenbogen. Es stellte sich Strabismus divergens ein, die R. Pupille war ad maximum erweitert, die L. enge. Temp. 39. Vormittags 10 thr trat der Exitus letalis unter den Erscheinungen der Herzschwäche ein.

\section{Autopsie. 18. Juli, Vormittags.}

Dura spinalis und weiche Häute stark injicirt, besonders nach dem caudalen Ende zu. Graue strichförmige Verfärbung der Hinterstränge des Rückenmarkes, Verwachsung der Dura mater mit den Schädelknochen über der Spitze. des Stirnhirns. Die Dura selbst erscheint injicirt, ist im Uebrigen aber frei von Veränderungen. Die grossen Sinus enthalten viel Blut- und Speckhautgerinnsel. Die weichen Häute sind getrübt und verdickt, in denselben befinden sich in der Gegend über dem Stirnhirn beiderseits frische Blutungen. Die Gefässe der Basis sind frei von Veränderungen, nur die rechte Carotis zeigt einen klaffenden Durchschnitt. Ependymitis granularis des Bodens des IV. Ventrikels. Das Gehirn zeigt eine gute Consistenz, ist nicht auffallend blutreich. Herdartige Erkrankungen oder sonstige pathologische Befunde sind nicht zu. erheben; so ist auch eine Verschmälerung der Rinde nicht zu constatiren.

Im Uebrigen ergab die Section im wesentlichen nachstehenden Befund: Gangränöse resp. infiltrirte Partien über dem Kreuzbein, den angrenzenden Theilen des Gesässes und den Ellenbogen. Geringe Vergrösserung des Herzens. Im Bulbus aortae zwei kleine, stecknadelkopfgrosse, atheromatöse Herde. Beide Lungen überall lufthaltig, in der rechten Lunge sehr starker Blutgehalt. 


\section{Mikroskopische Untersuchung.}

Nach der Exner'schen Methode wurden untersucht: Gyr. rectus, frontalis superior und Cuneus links.

Im Gyr. rectus sind die Tangentialfasern völlig geschwunden. In der Rinde zahlreiche Neurogliazellen und eine grosse Menge von Gefässen; vielfach sieht man neugebildete Gefässschlingen und Gefässsprossen.

Im Gyr. frontalis sup. fanden sich noch vereinzelte Tangentialfasern vor, im Uebrigen entsprach der Befund dem bei dem Gyr. rectus gefundenen.

Im Cuneus liess sich das normale dichte Fasernetz nachweisen, auch sonst waren Veränderungen nicht zu erkennen.

Rü ckenmark. Die weichen Häute sind in geringem Grade verdickt, sie bestehen aus mehr oder minder dichtgefügten Bindegewebszügen, welchen eine nicht gerade erhebliche Zahl runder Zellen mit grossen Kernen eingelagert ist. Die Zahl dieser Zellen ist auch nicht annähernd so gross, dass man von einer eigentlichen kleinzelligen Infiltration sprechen könnte. Die Verdickung der weichen Hänte ist auf der dorsalen Fläche stärker als auf der ventralen und nimmt im Allgemeinen nach dem caudalen Ende des Rückenmarkes zu. Die Zahl der Gefässe in den weichen Hänten ist vermehrt, die Mehrzahl der Gefässe, besonders der Venen ist stark mit Blut erfüllt; die Gefässwandungen zeigen normale Verhältnisse, nur an einzelnen Stellen ist eine geringe Verdickung zu constatiren, dieselbe ist vor Allem durch eine Dickenzunahme der Adventitia bedingt. Nirgends findet sich in der Ungebung der Gefässe eine kleinzellige Infiltration; ebenso fehlen endarteriitische Veränderangen. Im Halsmark ist das Septum posterius verbreitert und enthält breite, beinahe bis an die hintere Commissur heranreichende Bindegewebszüge, in welche eine Anzahl von Gefässen eingebettet ist. Auch hier findet sich eine Vermehrung der Bindegewebskerne und eine Einlagerung einer Anzahl von Rundzellen. Im Gegensatz hierzu war im Brustmark und Lendenmark von einem hinteren Septum nichts mehr zu erkennen.

Am gehärteten Präparate liess sich bereits makroskopisch eine ausgedehnte Verfärbung der HStr. nachweisen. Weigert'sche Markscheidenpräparate zeigten, dass die HStr. in ihrer ganzen Länge einem Erkrankungsprocesse anheimgefallen waren (Fig. 3). Verschont geblieben waren von demselben nur die ventralen Felder. Die äbrigen Gebiete der HStr. waren sämmtlich in allerdings sehr versohiedener Stärke von dem pathologischen Processe in Mitleidenschaft gezogen. Im Lenden- und unteren Brustmark hatte die Erkrankung. ihren stärksten Grad in dem Gebiete der Burdach'schen Stränge erreicht, während eine Zone am Rande, sowie eine keilförmige Parthie in der Nähe der hinteren Längsspalte und die hinteren Wurzelzonen von einer schwächeren Degeneration befallen waren. In dem mittleren Brustmark wiesen die stärkste Degeneration die vorderen Wurzelzonen und die Burdach'schen Stränge auf, gleichfalls mit Ausnahme des dorsalen Randes und eines mit der Spitze nach vorne gerichteten Keiles, welche Partien eine weniger starke Degeneration erkennen liessen; daneben bestand auch ein Bezirk stärkerer Degeneration in 
in der Nähe der hinteren Längsspalte. Eigenthümlicher Weise war in dem oberen Brustmark von dieser stärkeren Degeneration nur eine schmale Zone im Gebiete der hinteren Wurzelzone verschont geblieben. Im ganzen erschien aber in dem oberen Brustmark die Degeneration mit Ausnahme der stark degenerirten vorderen Wurzelzone nicht so ausgeprägt. Im Halsmark waren neben den ventralen Feldern die hinteren Wurzelzonen fast vollliommen frei von Degenerationsprocessen. Ganz ausgesprochen waren dieselben in den Burdachschen und Goll'schen Strängen, ausgenommen war hier nur eine schmale Zone an der Grenze dieser beiden Stränge, woselbst noch zahlreichere Fasern erhalten zu sein schienen. Ausserdem liess sich eine durch das ganze Rückenmark zn verfolgende, im Halsmark allerdings nur ganz schwache Degeneration der Lissauer'schen Felder cunstatiren. Schliesslich war ein fast vollständiger Untergang der Nervenfasern in den hinteren Wurzeln des Lenden- und Brustmarkes nachzuweisen: Diese Wurzeldegeneration liess sich bis zum Halsmarke hinauf verfolgen, war hier jedoch nur noch wenig stark. In den übrigen Gebieten der weissen Substanz und in den vorderen Wurzeln waren degenerative Erscheinungen nicht wahrzunehmen. In der grauen Substanz fiel die belle Verfärbung der Clarke'schen Säulen sofort auf. Ebenso konnte man auch bereits unter Zuhilfenahme schwacher Vergrösserungen einen Untergang der in die HH. einstrahlenden Fasern erkennen. Auch die graue Substanz der VH. erschien in ihren binteren und mittleren Parthien erheblich gelichtet. Ebenso fielen im Brustmark die Seitenhörner durch ibre spitze Gestalt und helle Farbe auf.

Dieser Befund konnte durch die Untersuchung mit mittleren und stärkeren Vergrösserungen noch wesentlich erweitert werden. Es zeigte sich, dass der Krankheitsprocess nicht vollkommen auf die HStr. und die graue Substanz beschränkt war. In dem Gebiete der PySSt. fanden sich zwischen anscheinend nicht weiter veränderten Nervenfasern mehr oder minder grosse Mengen von Myelinschollen. Daneben sah man eine allerdings kleine Anzahl von Nerven-. fasern, die eine Schwellung der Axencylinder oder eine Verbreiterung der Myelinscheide resp. bröckeligen Zerfall derselben erkennen liessen. Aehnliche Veränderungen fanden sich, allerdings nur ganz vereinzelt, auch in den übrigen Theilen der VSStr. Auch in der grauen Substanz, vor allem in ihren mittleren Theilen traf man hin und wieder auf Myelinschollen. In den Clarke'schen Säulen war nur eine sehr geringe Zahl, zum grössten Theile pathologisch veränderter Nervenfasern zu entdecken. Die Zahl der ans dem HStr. in die HH. eintretenden Nervenfasern war im Gebiete des Halsmarkes anscheinend nicht vermindert, weiter abwärts jedoch war ein erheblicher Schwund dieser Fasern nicht zu verkennen. In den hinteren Wurzeln trat der Untergang der Nervenfasern noch schärfer hervor; in den Wurzeln des Lendenund Brustmarkes erschienen nur noch ganz vereinzelte Fasern intact, es fanden sich hier in den Wurzeln eine grössere Zahl erweiterter Blutgefässe mit verdickten Wandungen. Im Halsmark war nur ein geringer Untergang von Fasern der HW. zu constatiren.

In den HStr. waren auch die bei Betrachtung mit schwächeren Systemen 
anscheinend von einer Degeneration freien Zonen nicht vollkommen von Krankheitsprocessen verschont. Auch an diesen Stellen sah man einzelne Myelinschollen und vereinzelte degenerirte Fasern. Recht eigenartig gestaltete sich das Bild in den degenerirten Bezirken der HStr. Es zeigte sich einmal, dass überall in allerdings sehr wechselndem Maasse noch Nervenfasern erbalten waren. Sodann konnte man wahrnehmen, dass beinahe die ganze degenerirte Zone mit zum Theil sehr grossen Myelinschollen übersät war. Dann liess sich auch bereits bei der Weigertfärbung erkennen, dass das gewucherte Stïckgewebe in den einzelnen Parthien der degenerirten Bezirke ein verschiedenes Aussehen hatte. Zum Theil erschien es mehr derbe und fester gefügt, in einer Art, wie man es gewöhnlich bei chronischen sclerosirenden Processen artrifft; zum Theil zeigte es einen lockereren Bau, und enthielt dann auch vielfach Lü̈cken, so dass es ein poröses Aussehen gewann. Es entsprachen dabei diese derberen Zonen den bei der Betrachtung mit blossem Ange am stärksten degenerirten Parthien also vor allem den vorderen Wurzelzonen resp. im Lenden- und unteren Brustmark gewissen Partien der Burdach'schen Stränge. Eine eigenartige Vertheilung liessen auch die eben erwähnten Myelinschollen erkennen, indem sie grade am spärlicbsten in diesen stärker sclerosirten Partieen anzutreffen waren.

Die Befunde an den nach van Gieson gefärbten Präparaten entsprachen den ebengeschilderten vollkommen, liessen dabei aber noch eine Reihe weiterer Einzelheiten erkennen. Auch sie zeigten, dass nicht nur die HStr. und die graue Substanz, sondern auch die übrigen Theile der weissen Substanz von einem krankhaften Process ergriffen waren. In dem Gebiete der PySSt. fand sich eine ganz geringe Wucherung der Neuroglia. Die Septen waren verbreitert, die Zahl der Neurogliakerne vermehrt. Dabei waren jene jetzt bereits so oft beschriebenen protoplasmareichen Neurogliazellen hierselbst in grösserer Zahl anzutreffen. Einmal handelte es sich hierbei um relativ grosse, runde, ovale oder auch mehr quadratisch gestaltete Zellgebilde, mit grossem runden oder ovoiden oder auch unregelmässig gestaltetem Kern. Daneben stiess man auf andere gleichfalls noch protoplasmareiche Zellen, die Ausläufer erkennen liessen, und schliesslich anch auf Zellen, die bereits eine Differenzierung in Zellkörper und Fibrillen aufwiesen. Ausserdem konnte constatirt werden, dass eine allerdings ganz geringe Zahl von Axencylindern Schwellungserscheinungen zeigte. Vereinzelte Nervenfasern schienen sich auch bereits in einem weiteren Zerfall zu befinden, dieselben hatten nicht mehr die normale, glänzend rothe Farbe, sondern sahen krümelig, bröckelig aus; manchmal lagen nebon ihnen innerhalb der die Fasern einscheidenden Gliahüllen mehr oder minder gut erhaltene Zellgebilde.

In den übrigen Gebieten der VSSt. waren ähnliche, allerdings viel weniger ausgebildete Veränderungen ganz vereinzelt anzutreffen.

Wie erwähnt wiesen die Weigert'schen Präparate darauf hin, dass der pathologische Process nicht in allen Gebieten der HStr. vollkommen gleichartig war. Diese Differenz trat in den van Gieson'schen Präparaten noch schärfer hervor, zugleich liessen diese aber auch einen näheren Einblick in die 
Structur des Gewebes erkennen und gaben so den Schlüssel für die Erklärung dieser an sich so auffallenden Thatsache. In den Gebieten, in welchen in den Weigert'schen Präparaten der stärkere Schwund des nervösen Gewebes zu finden war, und das Stützgewebe ein derberes Aussehen hatte, fand sich eine starke Wucherung der Glia vor. Diese Wucherung war hier dadurch ausgezeichnet, dass es zu der Entwicklung von mehr oder minder starken Zügen von Neurogliafasern gekommen war. Die Hauptmasse dieser Fasern war in der Längsrichtung des Rückenmarkes angeordnet, sodass man auf Querschnitten die einzelnen etwa noch erhaltenen Nervenfasern und die Gefässe von zahlreichen feinsten leuchtend rothen Pünktchen, den Querschnitten der Neurogliafibrillen, umgeben sah. In den grösseren Septen freilich waren auch starke Zïge horizontal verlaufender Fibrillen wahrzunehmen.

In den anderen weniger stark degenerirten Gebieten war das Verhalten der Glia wesentlich anders. Hier sah man ein locker gefügtes Netz, das zum Theil aus Neurogliafasern, zum grössten Theile jedoch aus den noch nicht zu starren Fasern umgebildeten Fortsätzen der so zahlreichen Neurogliazellen gebildet war. An einzelnen Stellen erschienen die Lücken dieses Netzes vollkommen leer, so dass dann diese Stellen ein wabenartiges Aussehen hatten. An anderen Stellen traf man in diesen Lücken mehr oder minder veränderte Nervenfasern an. Diese Nervenfasern hatten das eine mal einen verdickten, oft in Zerfall begriffenen Axencylinder, andere male erschien die Myelinscheide in Bröckel auseinander gefallen. Wieder andere male war der Axencylinder gewunden und geschlängelt, so dass man dann oft schraubenzieherartige Gebilde oder ganze Knänel von Axencylindersubstanz in den Schnitten vor sich hatte. Wieder an anderen Stellen konnte man neben diesen Axencylindern, und zwar in dem Raume, welchen normaler Weise die Myelinscheide hätte einnehmen sollen, rundliche Zellen oder zellartige Gebilde wahrnehmen. Einmal waren diese Zellen als solche noch gut erhalten, sie lagen dann dem Axencylinder an, andere male waren jedoch die Zellen wesentlich verändert. Zum Theil war ihr Protoplasma lörnig und nur wenig gefärbt, zum Theil erschien es in eine Anzahl blasser Körnchen zerfallen, zum Theil war von einer rosa Färbung überhaupt nichts mehr wahrzunehmen, das ganze Gebilde hatte vielmehr eine blasse Farbe, es präsentirte sich als ein kugelförmiges Gebilde, dessen Oberfläche eine wabenartige Zeichnung trug. Ebenso verschiedenartig wie der Bau des Protoplasmas war auch das Verhalten der Kerne. Da, wo das Protoplasma noch ein annähernd normales Aussehen aufwies, war auch der Kern nicht weiter verändert, er war gross und zeigte auf einem blassen Grunde mehr oder minder zahlreiche dunklere Körnchen oder netzförmige Figuren. In den grösseren ganz blassen Zellen fand sich meist ein dunkel gefärbter, kleinerer, länglicher, meist wandständiger Kern. In den zerfallenen Zellen war ein Kern nicht mehr nachzuweisen, es fand sich in denselben aber beinahe regelmässig eine kleinere oder grössere Zahl tief dunkel gefärbter Massen oder Pünktchen, die so an einander galagert waren, dass sie von derm Zerfall eines Kernes herzurühren schienen. Hin und wieder gelang es in den noch besser erhaltenen Zellen, kurze Stückchen oder wenigstens grössere 
Bröckel scharf roth gefärbter, und daher gut als solcher erkennbarer Axencylindersubstanz anzutreffen.

Wie erwähnt, waren in diesen Gebieten grosse Mengen jener protoplasmareichen Neurogliazellen aufzufinden. Es zeigten dieselben ein sehr vielgestaltiges Aussehen, das eine Mal handelte es sich um grosse, meist runde resp. längliche Zellen mit grossem, oft an der Peripherie gelegenem Zellkern. Vielfach war der Contour dieser Zellen aber auch unregelmässig gestaltet, indem das Protoplasma sich nach allen den Richtungen ausgebreitet zu haben schien, in denen es nicht auf Widerstand stiess; so füllte es, wenn ich mich so ausdrücken darf, die Lücken zwischen den benachbarten Nervenfasern, Gefässen oder sonstigen Neurogliaelementen wie ein Ausguss ans. So z. B. fand ich eine Zelle, deren Protoplasma um zwei Nervenfasern herumgeflossen war, sodass es so schien, als ob diese Nervenfasern die Zelle durchbohrt hätten. Ausserdem sah man Zellen, deren relativ breite Ausläufer sich nur auf eine geringe Entfernung von der Zelle hin erstreckten. Die Mehrzahl der Zellen liess jedoch bereits eine Differenzirung von Fibrillen erkennen. Hier hob sich der dunkel gefärbte, scharfe, glänzend erscheinende Rand der Zelle resp. der Fortsätze scharf gegen das blasse Protoplasma ab. Bei diesen Zellen erreichten die Fortsätze auch meistens eine ganz beträchtliche Länge. An anderen Zellen erschien der Process schon weiter vorgeschritten, hier waren die in die Fortsätze übergehenden Randpartien des Protoplasmas schon scharf gegen dasselbe abgesetzt und hatten schon ein direct fibrillenartiges Aussehen, das Protoplasma selbst war dann bereits in seiner Masse reducirt. Auch bei diesen Zellen war der Kern beinahe immer an der Peripherie der Zelle anzutreffen. Auffallender Weise lagen nicht selten 2 ja 3 derartige Zellen neben einarider, oft sogar deckten sie sich dachziegelartig, so dass man auch bei stärkeren Vergrösserungen auf den ersten Blick glauben konnte, mehrkernige Zellen vor sich zu haben.

Diese ganzen, so verschiedenartig erscheinenden Krankheitsprocesse waren jedoch räumlich nicht von einander geschieden, einmal griff der zuerst geschilderte, mehr sklerosirende Process auch auf die anderen Gebiete'ohne scharfe Grenze über, und andererseits fanden sich die zuletzt geschilderten Befunde in allerdings sehr beschränktem Maasse auch innerhalb der sklerosirten Partien vor. So sah man auch hier neben vereinzelten, noch vollkommen erhaltenen Nervenfasern, eine kleine Zahl von Fasern, die jene degenerativen Veränderungen aufwiesen, und konnte auch hier zwischen den derberen Neurogliafasern eine kleine Zahl jener protoplasreicheren Neurogliazellen, in all ihren verschiedenen Stadien auffinden.

Sodann konnte man an der Hand dieser Präparate nachweisen, dass auch die anscheinend garnicht veränderten Zonen der H.Str., von dem krankhaften Processe nicht vollkommen verschont gehlieben waren. Auch hier fanden sich vereinzelt degenerirende Fasern und Wucherungen der Neuroglia.

Auf Längsschnitten waren diese Verhältnisse in entsprechender Weise zu constatiren. An den schon mehr sklerosirten Stellen sah man dicke Züge eng an einander gelagerter Neurogliafasern, zwischen welchen nur hin und 
wieder einzelne wohlerhaltene, oder in den verschiedenen Stadien des Zerfalls befindliche Axencylinder anzutreffen waren. Daneben traf man auf Nervenschläuche, in welchen Zellen oder Zellreste aufzufinden waren. Dazwischen waren dann auch protoplasmareiche Neurogliazellen verschiedenster Gestalt wahrzunehmen. In den anderen Partien stiess man auf das lockere Neurogliagewebe mit jenen grossen protoplasmareichen Gliazellen. Sehr schön kounte man auf den Längsschnitten die Auflnäuelung der Axencylinder wahrnehmen und auch constatiren, dass die Axencylinder in ibrem Verlaufe unterbrochen waren.

Dass auch die grane Substanz in ausgedehntem Maasse erkrankt war, hatten gleichfalls bereits die Weigert'schen Präparate gezeigt; auch an den yan Gieson'schen Präparaten liess sich der Schwund der Fasern innerhalb der Clarke'schen Säulen, sowie der mehr oder minder weitgebende Untergang der in die H. St. einstrablenden Collateralen erkennen. Vielfach sah man in den Clarke'schen Säulen gequollene oder zerfallene Axencylinder. Ebenso erschienen auch in diesen Präparaten die mittleren Theile der grauen Substanz gelichtet. Auch hier stiess man vielfach auf degenerirende Axencylinder und wuchernde Neurogliazellen. In den Seitenhörnern waren die Ganglienzellen ganz nahe an einander gerückt, so dass dieselben ganz spitz erschienen.

In der grauen Substanz fanden sich mehrfach, in der weissen Substanz nur ganz vereinzelt kleine capilläre Blutungen. Irgendwelche besonderen Veränderungen waren in der Umgebung dieser Blutungen nicht zu constatiren. Die Gefässe waren im Allgemeinen mit Blut stark gefüllt, zum Theil waren sie übermässig ausgedehnt und wiesen auch theilweise verdickte Wandungen anf. Diese Verdickung der Wandungen betraf vor Allem die Adventitia. Nirgends fanden sich endarteriitische Wucherungen oder eine kleinzellige Infiltration in der Umgebung der Gefüsse.

Ausserdem wäre noch zu bemerken, dass in den H. Str. zahlreiche, im Uebrigen nur vereinzelte Corpora amylacea apzutreffen waren.

In den nach Nissl behandelten Präparaten fiel gleichfalls ohne Weiteres die grosse Zahl der Kerne in den Hintersträngen auf. Die multipolaren Vorderhornzellen waren nur noch zum Theil normal. Auch in diesen, sonst normal erscheinenden Zellen traf man, wie in den sogleich zu beschreibenden, krankhaft veränderten reichliche Mengen ron Pigment an. Bei einer grossen Anzahl der V. H.-Zellen war auch die nicht färkbare Substanz mitgefärbt, bei einem Theile dieser Zellen war die färbbare Substanz in dicken, tief dunkelblauen, oft an der Peripherie der Zellen gelegenen Ballen angehäuft. An anderen Zellen waren ausgesprochene Zeichen des Zerfalls nachzuweisen; hier war oft der Kern als solcher nicht mehr zu erkennen, der ganze Zellleib erschien aus lrrümoligen, hellblauen Massen zusammengesetzt, zwischen welchen noch einzelne tief dunkelblaue Klumpen von Nissl-Substanz anzutrefien waren. Von anderen Zellen war sozusagen nur noch ein Schatten übrig, es lagen hier nur noch krümelige resp. feingekörnte hellblaue Massen beieinander, die in ihren Contouren noch die Umrisse der ehemaligen Zelle erkennen liessen.

Auch in den Zellen der Clarke'sen Sänlen war reichlieb Pigment vor- 
handen, vielfach hatten sie wandständige Kerne. Bei einer Reihe dieser Zellen war das Centrum der Zellen mehr gleichmässig blau gefärbt, während in der Peripherie gröbere Massen von Nissl-Substanz lagen.

In den Mittelzellen und in den grösseren Zellen der Hinterhörner machte sich gleichfalls vielfach lirümeliger Zerfall resp. ein Zusammensickern der färbbaren Substanz bemerkbar. In den kleineren H. H. -Zellen fanden sich oft kileine Anhäufungen von färbbarer Substanz in der Nähe der Kerne. Die Kernmembran war oftmals gefaltet.

Hirnstamm. Der Stamm wurde bis zum proximalen Ende der Brücke untersucht. Die H. Str.-Erkrankung liess sich bis zum oberen Ende der Kerne der Burdach'schen und Goll'schen Stränge verfolgen. Auch hier wies der Process die beiden im R. M. nachweisbaren verschiedenartigen Formen auf. Die am stärksten degenerirte, mehr sklerosirte Partie nahm hier einen schmalen Strich ein. Im untersten Theile des Stammes in einer Höhe, in welcher die Pyramidenkreuzung gerade beginnt, zieht dieser schmale Streifen von dem ventralen Ende der hinteren Längsspalte nach hinten und aussen und liegt so aussen den Goll'schen Strängen an. Der Goll'sche Strang selbst zeigt nur eine schwache Degeneration, stärker degenerirt érscheint beiderseits in den Burdach'schen Strängen ein halbmondförmiges, aach vorne offenes Feld, welches jedoch nicht die Peripherie errejcht. Die Randzone ist vielmehr frei von krankhaften Processen; in den übrigen Bezirken der Burdach'schen Stränge ist ein geringer Ausfall von Fasern zu constatiren, der jedoch in den der grauen Substanz des Halses, des Hinterhirns und der Commissur benachbarten Partien nur ganz minimal ist.

In den proximalwärts gelegenen Schnitten findet sich die strichförmige sklerosirte Partie zwischen den Nuclei der Funiculi graciles und coneati; sie zieht hier, von dem Winkel zwischen diesen beiden Kernen schräg nach hinten und aussen verlaufend, bis nach der Peripherie. Ein stärker degenerirtes Feld nimmt eine halbmondförmige Zone um die Kerne der Burdach'schen Stränge ein, von denen es jedoch durch eine schmale, fast normal erseheinende Partie von Nervenfasern getrennt bleibt. Ebenso ist auch die Peripherie dieses Stranges nicht erkrankt. In den Goll'schen Strängen ist auch in diesen Höhen eine leichte Degeneration nachzuweisen.

Auf die histologischen Details glaube ich im Hinblick auf die vorher gegebenen Schilderungen nicht weiter eingehen zu müssen.

In der absteigenden Trigeminuswurzel sind degenerative Vorgänge nicht aufzufinden, ebenso wenig lässt sich eine Erkrankung im Gebiete der Schleife constatiren. In den Py. trift man auf einzelne geschwollene Fasern, doch snd hier sehr viel weniger Krankheitserscheinungen wahrzunehmen, als in den Py. St. des R. M.

In den höheren Partien des Stammes lassen sich innerhalb der einzelnen Strangsysteme pathologische Veränderungen nicht entdecken, auch hier ist von einer Erkrankung der absteigenden Trigeminus- und Vago-Glossopharyngeuswurzel nichts wahrzunehmen. Ebensowenig wiesen die Kerne Kranliheitsprocesse auf. Es mag dabei dahingestellt bleiben, ob nicht etwa doch, wie es 
nach dem Befunde innerhalb des R. M. zu erwarten wäre, Structurveränderungen an den Ganglienzellen vorhander waren, die mir boi den angewandten Methoden entgehen mussten; eine Untersuchung nach $\mathrm{N}$ iss 1 konnte nicht vorgenommen werden. Erwähnt werden möge noch besonders, dass das Netz der Nervenfasern innerhalb der sensiblen und motorischen Nervenkerne eine Rarefication nicht zeigte.

Am Boden des IV. Ventrikels waren zahlreiche Ependymgranulationen aufzufinden. Auffallend war in den gewucherten Partien die grosse Zahl der Neurogliakerne und die geringe Dichte des Neurogliafilzes. Das Epithel war über der Mehrzahl der Granulaiionen erhaiten, an einzelnen Stellen war es zu einer Abschnürung von Epithelschläuchen gekommen.

Ebenso wie im R. M. fiel auch im Stamme der Zahl die starke Füllung and Erweiterung der Gefässe auf. Die Wandungen derselben waren vielfach ganz allgemein verdickt; eine. Wucherung der Intima oder einer kleinzelligen. Infiltration der Umgebung der Gefässe war auch hier nicht nachzuweisen. Die weichen Häute zeigten dasselbe Bild wie die Häute des R. H., speciell möge angefuhrt werden, dass auch hier die Arterien, in specie die Art. basilaris, Wucherungen der Intima nicht erlennen liessen.

Grossbirn. Die weichen Häute, deren Verdickung bereits bei den makroskopischen Untersuchungen constatirt werden konnte, waren aus mehr oder minder dichten Bindegewebszügen gebildet, zwisehen welchen sich recht zahlreiche Rundzellen vorfanden. Vor allem waren diese Anhäufungen von Rundzellen in der Umgebung der Gefässe anzutreffen, es war ihre Ansammlung daselbst vielfach so mächtig, dass man direct von einer Infiltration sprechen konnte. Derartige Stellen erschienen dann auch in den van Giesonschen Präparaten bereits bei makroskopischer Betrachtung als blaue Punkte resp. Striche. In der beigegebenen Figur 4 habe ich eine dieser Stellen, an welcher jedoch diese Infiltration noch nicht ihren stärlssten Grad erreicht hat, wiedergegeben. Sehr schön konnte man vielfach an derartigen Stellen wahrnehmen, dass diese Infiltration sich trichterförmig in den adventitiellen Räumen bis in die Rinde hinein erstreckte. Die Gefässe waren dabei fast sämmtlich strotzend mit Blut gefüllt. Im Uebrigen jedoch waren nennenswerthe Veränderungen an denselben nicht zu erkennen, speciell fanden sich nirgends endarteriitische Processè. Die Zahl der Gefässe war ganz ausserordentlich gross. An einzelnen Stellen fanden sich innerhalb der weichen Hänte kle ne Blutungen. Alle diese Veränderungen waren im Gebiete des Stirnbirns am stärksten ausgesprochen und nahmen nach dem Occipitalpole zu an Intensität ab; so war wenigstens an den Schnitten aus den Hinterhauptappen haum noch etwas von jener Rundzellen-Infiltration wahrzunehmen.

Um Uebersichtspräparate zu gewinnen, wurden Frontalschnitte ron dem. ganzen rechten Stirn- and Hinterhauptslappen verfertigt. Ausserdem wurde ein die Central- und Paracentralwindungen mit der unter denselben gelegenen weissen Substanz umfassendes Stiuck in Schnitte zerlegt und schliesslich, um ganz feine (8-10 n.) Sohnitte zu erhalten, eine Reihe kleinerer Blöcko geschnitten. 
Ebenso wie die weichen Häute des Gehirns wiesen auch die Schnitte aus den einzelnen Partien des Gehirns ein sehr verschiedenes Aussehen auf. Es waren im Gebiete des Stirnhirns sehr schwere Veränderungen anzutreffen, während im Occipitallappen nur sehr geringgradige krankhafte Processe zu constatiren waren.

Im Stirnhirn fiel schon bei der Untersuchung mit schwächeren Systemen die ausserordentlich grosse Zahl und starke Füllung der Gefässe auf. An vielen der mittleren und stärkeren Hirngefässe fand sich theils in ihren adventitiellen Scheiden, theils auch in ihrer Umgebung eine ziemlich starke Infiltration von Rundzellen vor. Es war dieselbe im Allgemeinen wesentlich stärker, als man sie sonst in den Gehirnen von Paralytikern antrifft. Wies schon die grosse Zahl der Gefässe darauf hin, dass es hier wirklich zu einer Vermehrung, zu einer Nenbildung von Gefässen gekommen war, so wurde dieselbe auch dadurch noch sichergestellt, dass sich auch in diesen Präparaten, ebenso wie in den Exner-Präparaten, Gefässsprossen und neugebildete Schlingen auffinden liessen. Hin und wieder stiess man auf kleine frische Blutungen in der Umgebung der Gefässe, an einzelnen Stellen sah man auch, dass Blutungen in den untersten Lagen der weichen Häute sich bis in die Rinde hinein erstreckten. Die Zahl und Lagerung der Ganglienzellen in der Rinde liess eine Abweichung von der Norm nicht erkennen. Die Neuroglia wies eine allgemeine, wenn auch nicht allzu starke Wucherung auf, wenigstens erschien die Zahl der in der Rinde und in der weissen Substanz gelegenen Neurogliakerne deutlich vermehrt. Dabei waren in der weissen Substanz - es war dies besonders gut auf den feineren Schnitten zu erkennen - ganz ausserordentlich viele joner Neurogliazellen mit protoplasmareichem Leibe und excentrisch gelagertem Kerne anzutreffen. Eine weitere auffallende Erscheinung innerhalb der weissen Substanz bestand darin, dass sich in ihr bald weniger dicht, bald dichter gedrängt minimale, meist kreisrunde, nicht scharf begrenzte Lücken vorfanden. Bei eingehenderer Betrachtung zeigte es sich, dass die Mehrzahl dieser vermeintlichen Lücken von rundlichen, ganz blassen, vielfach dzörnig erscheinenden Zellen eingenommen war. Allem Anscheine nach handelte es sich hier um Körnchenzellen, deren fetthaltige Bestandtheile bei der Härtung ausgelaugt waren. Sehr viel schwerere Veränderungen wies die Neuroglia in der obersten Rindenschicht auf. Hier fand sich ein dichtes Gewirr von Neurogliafasern vor, deren Zusammenhang mit den zahlreichen Neurogliazellen noch auf das beste zu constatiren war. Dabei handelte es sich hier meist um jene protoplasmaarmen Neurogliazellen mit kleinem Kern. An einzelnen Stellen war das Netz der Nearogliafasern so dicht, dass man einen vollständigen Filz von Fasern vor sich hatte, in welchem dann die Kerne eingelagert erschienen. Hin und wieder war es zu dieser Verdichtung der Glia grade unter der Oberfläche der Rinde gekommen, es waren dann hier die einzelnen Fasern meist parallel und senkrecht zur Rinde angeordnet, sodass sie einen dichten Saum bildeten. Dieser war dabei selbst meist vollkommen frei von Kernen, während sich unterbalb desselben fast immer sehr zahlreiche Kerne vorfanden. In der Fig. 4 ist dieses Verhalten angedeutet. 
Zu erwähnen währe noch, dass diese Veränderungen nicht etwa immer an den Stellen besonders ausgeprägt waren, an welchen die kleinzellige Infiltration der weichen Hänte besonders stark war.

In den Schnitten aus der Gegend der Centralwindungen waren im wesentlichen die gleichen Veränderungen anzutreffen, nur erreichten sie hier auch nicht annähernd die gleiche Stärke.

Im Hinterhauptslappen war von krankhaften Veränderungen kaum noch etwas zu entdecken. Es fiel jedoch anch hier die starke Füllung der Gefässe auf. Zudem fand sich auch, wenn auch nur vereinzelt, eine geringe kleinzellige Infiltration in der Umgebung der Gefässe vor.

Die Weigert'schen Markscheiden-Präparate bestätigten den nach der Exner'schen Methode erhobonen Befund. In den Schnitten aus den Centralwindungen, welche nach der Exner'schen Methode nicht untersucht waren, war ein ausgesprochener Faserschwund zu constatiren, immerhin war bier noch eine ganze Anzahl von Tangentialfasern und Fasern des intra- und supraradiären Fasernetzes anzutreffen.

Kleinhirn. Auch ans dem Kleinhirn wurden eine Reihe von Schnitten angefertigt. Dieselben ergaben nicht mit Sicherheit einen pathologischen Befund; vielleicht war die Zahl der Neurogliakerne auch hier etwas vermehrt.

Schliesslich mögen hier noch die Krankengeschichten von zwei Patienten wiedergegeben werden, bei welchen zwar die Diagnose Dementia paralytica nicht mit Sicherbeit hatte gestellt werden können, bei denen es sich aber doch vielleicht um dieses Leiden gehandelt hat.

L. K., geb. 9. Juni 32, aufg. 22. April 84, gest. 2. Mai 84. - Keine Heredität, normale Entwicklung. Hatte als eifriger Geschäftsmann und Speculant vielfach geschäftliche Aufregungen. Nach alleriei geschäftlichen Aufregungen trat in der Nacht vom 21. zum 22. April eine erhebliche Erregung ein, welche seine sofortige Ueberführung nach der Anstalt nothwendig erschienen liess. Während der mehrstïndigen Wagenfahrt tobte er und musste andauernd von seinen Begleitern festgehalten werden. Auch bei der Aufnahme war er über alle Maassen erregt. Fine Untersuchung war unmöglich. Diese Erregung blieb auch weiterhin bestehen. Patient raste rollkommen nackend in seinem Isolirzimmer umher, schlug und trat um sich, sobald jemand in seine Nähe kam. Bei den Versuchen, ihm Nabrungsmittel zu geben, sträubte er sich sinnlos. Seine sprachlichen Aeusserungen waren vollkommen verwirrt; von den an ihn gerichteten Fragen nahm er nicht die geringste Notiz. Nach einigen Tagen stellten sich ganz incohärente Delirien ein, und warde sein Verhalten immer triebartiger. Nur ganz vorübergehend wurde er am 27. insoweit klar, dass er seine Personalien richtig angeben konnte. Am Norgen des 2. Mai trat, nachdem Patient in der Nacht noch ganz colossal erregt, gewesen war, ein Collaps ein. Der Puls wurde klein, die Pupillen weit, Zuckungen im Facialisgebiet, besonders auf der rechten Seite. Die Kniephänome waren nicht auszulösen. Um 9 Uhr Vormittags trat der Exitus ein.

Autopsie. Hirngewicht 1360. Meningealvenen strotzend gefüllt, weiche 
Häute über dem Stirn- und Scheitellappen entlang den Gefässen stellenweise getrübt, besonders links. Ganz mächtige Trübung der Pia über den Gyr. recti. Querschnitte der Art. carotid. klaffen. Ependym der Ventrikel zart; keine Herderkrankungen. Rückenmark makroskopisch ohne Besonderheit. Bei mikroskopischer Untersuchung finden sich in den HStr. in den Wandungen einzelner Gefässe Körnchenzellen.

K., geb. 23. September 50, aufg. 17. April 91, gest. 22. April 91. Der Kranke wurde der Anstalt Nachts zugeführt. Anamnestische Angaben waren nicht zu erhalten. Seine Begleiter konnten nur angeben, dass er erst seit einigen Tagen lrank sei und in der letzten Nacht getobt habe. Der Patient war sehr erschöpft, er erschien vollkommen verwirrt, stierte mit weitoffenen Augen vor sich hin, reagirte nicht auf Fragen oder Anreden. Er sah dabei ängstlich aus und stiess einige unzusammenhängende Worte hervor. Was mit ihm auch vorgenommen wurde, allem setzte er einen heftigen passiven Widerstand entgegen. Er schlief in der Nacht leidlich, war am nächsten Morgen rubiger, aber vollkommen unorientirt, redete zusammenhanglos vor sich hin, euphorische Stimmung. Des Abends wurde er wieder unruhiger, wollte das Essen nicht nehmen, schimpfte und schrie, spuckte fortwährend aus, behauptete Schmutz und Gift läme ihm in den Mund; dabei euphorisch und gänzlich verwirrt. Leider ist ein eingehender Status nicht vorbanden, notirt ist in der Krankengeschichte nur, dass die P.S.R. vorhanden gewesen sind, und der Urin einen starken Eiweisgehalt gehabt habe. Am 19. April Erscheinungen der Pneumonie. Temp. 40,7, P. 132, R. 40, RHU. Dämpfung, lautes Bronchialathmen, pneumonisches Sputam. Bis zum Tode sehr unruhig, delirirend.

Gehirngewicht 1310. Dura über dem Stirnhirn schlaff. Venen der Arachnoidea stark gefüllt; weiche Häute über Stirnhirn und Scheitellappen fleckweiso leicht verdickt. Oedem der weichen Häute. "Windungen des Stirnhirns erscheinen etwas schmal bei breiten Furchen, doch ist kein höherer Grad von Atrophie erkennbar. Im Lendenmark des Rückenmarkes deutliche graue Verfärbung der HStr." Lobäre Pneumonie.

Untersuchung nach Exner: Im Gyr. rectus sind die obersten Tangentialfasern bis auf vereinzelte geschwunden, während die tieferen noch erhalten sind. Im Gyr. frontal. superior und in der Brocaschen Windung, sowie in den Occipitalwindungen ist ein Faserschwund nicht aufzuweisen.

In demselben Zeitraume fanden in der hiesigen Anstalt 54 an $\mathrm{Pa}$ ralyse leidende Frauen Aufnahme. Von diesen können 4 Krankheitsfälle hier nicht in Betracht kommen, da jede Anamnese feblt. Erwähnt werden möge jedoch, dass alle diese 4 Frauen bereits bei ihrer Aufnahme die Zeichen einer weit vorgeschrittenen Demenz darboten, sodass man annehmen muss, dass sie schon längere Zeit krank waren. Von diesen 50 Frauen verstarben 6 im ersten Jahre nach Ausbruch der Paralyse. Von diesen scheiden für die vorliegende Betrachtung 4 Kranke 
ohne weiteres aus; 2 derselben gingen an Tuberculose za Grunde; eine dritte Kranke erlag einem Carcinoma ventriculi, welches zu weitgehender Metastasenbildung geführt hatte. Eine 4 . Kranke, welche im 10. Monat nach Ausbruch der Paralyse verstarb, erlag einer Pyelonephritis. Eine 5. Kranke - dieselbe könnte hier in gewissem Sinne in Betracht kommen - ging nach einer Krankheitsdaner voi 7 Monaten in Folge von Erstickung zu Grunde. Ihre Krankengeschichte ist von Tuczek in seiner Arbeit als Fall III wiedergegeben worden. Bei dieser Kranken steigerte sich die Erregung gegen Ende ihres Lebens - um Tuczek's Worte zu gebrauchen - zu delirienartiger Höhe. Es würde somit eigentlich allein der 6. Fall als hierhergehörig übrig bleiben. Auch bei diesem kann ich von einer Wiedergabe der Krankengeschichte absehen, dieselbe findet sich in der Tuczek'schen Arbeit als Fall II. Die Patientin M., geb. März 1849, aufgenommen 25. Mai 1892, gest. 25. Juni 1882 erkrankte Ende März 1882 und ging demnach nach 3 monatlicher Krankheitsdauer zu Grunde.

Auffallender Weise wären somit im Verhältniss viel mebr Frauen als Yänner im ersten Jahre nach Ausbruch der Paralyse ihrem Leiden erlegen, nämlich $12 \mathrm{pCt}$. gegenüber $7,36 \mathrm{pCt}$. bei Männern. Es dürfte jedoch diese Zahl bei der. geringen Gesammtzahl der paralytisch kranken Frauen eine Bedeutung nicht besitzen. An demselben Fehier leiden auch die sonstigen Statistiken, immerhin möge hier angeführt werden, dass Heilbronner ${ }^{1}$ ) unter 86 Frauen 18 fand, die im ersten Jahre nach Beginn der Paralyse zu Grunde gingen, 20,93 pCt., während diese Zablen bei Sprengeler, welcher 36 paralytisch kranke Frauen zur Untersuchung heranziehen konnte, sich auf $2=6,6$ pCt.stellen. Grepp in $\left.{ }^{2}\right)$ zählt unter seinen 26 Fällen von Franenparalyse nur 1 auf, in welchem die Erkrankung im ersten Jahre zum Tode führte. Ein ganz ähnliches Resultat giebt $\mathrm{Kundt}^{3}$ ) an, der unter 35 paralytisch kranken Frauen auch nur eine fand, die im ersten Jahre nach Ausbruch der Paralyse bereits ihrem Leiden erlegen war. Ein ganz ausserordentlich hoher Procentsatz ist von Müller angegeben, welcher unter 79 paralytischen Frauen $19=24.1 \mathrm{pCt}$. Todesfälle im ersten Jahre der Erkrankung fand.

Die Zahl der männlichen Paralytiker, welche im ersten Jahre nach Ausbruch ihrer Erkrankung zu Grunde gehen, würde somit nach den in Marburg gemachten Erfahrungen sehr klein sein. Von 326 paralytisch

1) loc. cit.

2) Ueber 26 Fälle von progressiver Paralyse bei Franen. Zeitschr. für Psych. Bd. 46.

3) loc. cit. 
kranken Männern starben nur 24 im ersten Jahre nach Ausbruch der Paralyse, also nur 7,36 pCt. Dabei ist die Zahl der im ersten Jahre des Leidens verstorbenen 24 Mämner sicherlich nicht zu klein, höchstens könnte sie noch zu gross sein, da vielleicht doch noch der eine oder der andere dieser 24 Kranken schon länger krank war, und nur die Anamnese nicht genau genug gewesen ist. Von diesen 24 Fällen vort Paralyse bei Yännern können nach den in der Einleitung ausgefübrten Gründen 9 für die bier aufgeworfene Frage nicht weiter in Betracht kommen, da sie ja nicht ihrer Paralyse oder einer mit derselben direct verbundenen Complication erlegen sind:

Von den nach dem Ausscheiden der vorher erwähnten Fälle verbleibenden 15 Fällén zeigen 11 Kranke einen Krankheitsverlauf, der allerdings schnell zum Tode führte. Mit Ausnahme der beiden an letzter Stelle angeführten Kranken Fritz $\mathrm{H}$. aus Cassel und Franz H. aus Cassel bieten die Krankengeschichten jedoch irgend etwas besonderes nicht dar; es finden sich allerdings die allerverschiedenartigsten Symptome vor, aber in einer Verknüpfung, wie wir sie auch bei der gewöhnlichen Paralyse antreffen. Das einzige, wodurch diese Krankheitsprocesse auffallen, ist ihr schneller zum Tode führender Verlauf. Es würde sich vielleicht empfehlen, derartige Krankheitsbilder als schnell verlaufende, acute Paralysen zu bezeichnen.

Die Krankengeschichte der beiden in dieser Gruppe zuletzt angeführten Kranken Fritz H. aus Cassel und Franz H. aus Cassel zeigen dagegen einen etwas andersartigen Verlauf.

Bei Fritz H. aus Cassel begann die Paralyse ohne besonders auffallende Krankheits-Erscheinungen. Nach beinahe einjährigem Bestehen der Erkrankung wurde er, da Lues bei ihm sicher vorangegangen war, und auch noch Anzeichen von bestehender Lues bei ihm wahrzunehmen waren, einer Schmierkur unterzogen, die nach Verbrauch von $40 \mathrm{~g}$ grauer Salbe wegen einer allgemeinen Verschlechterung seines Befindens. abgebrochen werden musste. Es stellte sich eine hochgradige maniacalische Erregung ein, die schnell einen triebartigen Character annahm und schliesslich in einen deliriumartigen Verlauf überging, in welchem der Kranke bereits 10 Tage nach seiner Aufnahme in die Anstalt und circa 14 Tage nach Beginn der stärkeren. Erregung seinem Leiden erlag.

Der zweite Kranke, Franz H. aus Cassel, ist schon insofern interessant, als es sich bei ihm sicherlich um ein in erheblichem Grade imbecilles Individuum handelte. Das Auftreten der Paralyse bei Imbecillen ist ja auch sonst öfters beschrieben worden, konnte Tuczek doch sogar einmal über einen Fall von Dementia paralytica bei einem Idioten 
berichten. Auch bei dem Franz H. nahm die Erkrankung zuerst den gewöhnlichen Verlauf. Es trat dann aber circa 4 Monate nach dem Beginn der Erkrankung eine schwere paralytische Attaque auf, die eine auffallend starke Parese zurïckliess. Weitere 2 Monate darauf erlitt der Kranke eine zweite Attaque, an welche sich ein fieberhafter Zustand anschloss, und zugleich der Symptomencomplex des acuten Deliriums sich entwickelte. In diesen beiden Fällen würden wir also Paralysen vor uns haben, die vorerst den gewöhnlichen Verlauf nehmen, in denen dann aber später die Kranken in einen Zustand schwerster, deliriumartiger Erregung verfallen und in diesem zu Grunde gehen. Dabei will es mir scheinen, als ob in diesen beiden Fällen ein ursächliches Moment für den Ausbruch dieses deletären Symptomencomplexes wohl zu finden wäre. In dem zweiten Falle sahen wir diesen deliriumartigen Zustand sich entwickeln nach einem apoplectiformen Insult und dem gleichzeitigen Ausbruch einer schweren Phlegmone. In dem ersten Falle schliesst sich diese schwere Erregung direct an eine mercurielle Kur an. Ich werde späterhin noch Gelegenheit nehmen, hierauf zurückzukommen.

Während wir bei diesen Fällen einen deliriumartigen Zustand nur als das Finale eines bis dahin chronischen Processes vor uns haben, treffen wir bei den letzten 4 Kranken ein Krankheitsbild an, in welchen diese schwersten Krankheitserscheinungen - es mögen hier vorläufig nur die klinischen Krankheitsärsserungen in Rücksicht gezogen werden bereits bei dem Beginne der Erkrankung oder wenigstens sehr bald nach dem Ausbruche des Leidens sich geltend machten. Leider ist die erste dieser Krankengeschichten etwas kurz gehalten, eine mikroskopische Untersuchung fehlt. Immerhin ist die Schilderung doch so genau, dass man sich ein genügend klares Bild machen kann und der makroskopisch erhobene Befund genügend characteristisch. Aufmerksam. möchte ich bei demselben besonders auf den ausserordentlich grossen Blutreichthum des Centralnervensystems machen. Der Kranke erlag seinem Leiden circa 6 Wochen nach dem Auftreten der ersten Prodromalerscheinungen.

Bei dem zweiten Kranken G. trat nach einem kurzen Prodromalstadium erhöhter Reizbarkeit ein vorübergehender eigenartiger Zustand (paralytische Attaque) auf. Einen halben Monat später stellte sich Erregung ein, die dann ganz schnell in einen deliriumartigen Zustand überging, in welchem der Kranke in Kürze seinem Leiden erlag. Irgend eine Ursache für diese schwere Erkrankungsform war nicht aufzufinden.

Bei dem 3. Kranken H. verlief die Erkrankung in mancher Beziehung ähnlich. Anch bei ihm fand sich nur ein kurzes Prodromal- 
stadium, an welches sich obne erkennbare Ursache ein deliriumartiger Symptomencomplex anschloss.

Ein ganz besonderes Interesse bietet die Geschichte des 4 . Kranken. Der Patient lebte in den günstigsten Verhältnissen, war allgemein beliebt und geachtet, war mässig in jeder Beziehung, sodass, abgesehen von der specifischen Infection, irgend ein ätiologisches Moment für seine Erkrankung nicht aufzufinden war. Bei diesem Kranken machten sich April 1896 Erscheinungen einer Erkrankung der ${ }^{*} H S t$. des Rückenmarkes geltend; er wurde einer energiscben Schmierkur unterzogen, die durch eine Badekur in Tölz unterstützt wurde. Diese antisyphilitischen Kuren waren sehr intensiv, in circa 2 Monaten wurden $215 \mathrm{~g}$ verbraucht. Am 24. Juni fiel Patient zum ersten Male auf, am 26. Juni trat ein paralytischer Anfall ein, am 28. Juni machten sich Geruchs- und Gehörstäuschungen geltend, am 5. Juli zeigte sich eine sich schnell steigernde Erregung, die am 8. Juli in ausgesprochene Tobsucht und dann in einen deliriumartigen Zustand überging. Der.Tod trat am 17. Juli ein. Wir haben somit einen ganz ausserordentlich rapiden Krankheitsverlauf vor uns, der in circa $2 \frac{1}{2}$ Monaten nach dem Auftreten der ersten Erscheinungen von Seiten des Nervensystems und noch nicht einen Monat nach Einsetzen der ersten psychischen Krankheitserscheinungen zum letzten Ende führte.

Es würden demnach aus dem doch schon immer nenuenswerthen Krankenmateriale der Marburger Klinik nur diese 4 Fälle übrig bleiben, bei denen man ron einer wirklich galoppirenden, foudroyanten Paralyse sprechen könnte. Es empfiehlt sich wohl auch, für diese Verlaufsform eine derartig kurze, prägnante Bezeichnung beizubehalten, und unter derselben jene Krankheitsbilder zusammenfassen, in welchen nach einem relativ kurzen Prodromalstadium sofort diese schweren deliriumartigen Erregungszustände mit hochgradigster Verwirrtheit und Bewusstseinsstörung einsetzen. Es würde wenigstens auf Grund des Marburger Materials diese Verlaufsform zu den Seltenheiten gehören, da sich unter 335 paralytisch kranken Männern nur 4 fanden, die dieseñ Krankheitstypus zeigten, 1,19 pCt. Diese $\mathrm{Zahl}$ würde vielleicht insofern ein wenig zu erböhen sein, als noch jene beiden zu allerletzt angeführten Krankheitsfälle hierhergerechnet werden könnten, bei denen eine sichere Diagnose nicht hatte gestellt werden können. Rechnet man diese beiden Fälle der galoppirenden Paralyse zu, so hätten wir auf 337 paralytisch Kranke 6 foudroyant verlaufende Fälle: 1,78 pCt.

Von den Frauenparalysen würde nur der eine von Tuczek beschriebene Fall hierherzurechnen sein. 
Es erübrigt nun noch das Resultat der anatomischen Untersuchung, soweit dies nicht bereits geschehen ist, einer Besprechung zu unterziehen.

$\mathrm{Zu}$ meinem grossen Bedauern ist das Centrahnervensystem des ersten dieser 4 Kranken mikroskopisch nicht untersucht worden. Makroskopisch zeigte es einen Befund, wie man ihn oft genug bei Paralytikem erheben kanu. Auffallend ist jedoch einmal das hohe Gewicht des Gehirns 1410, welches an sich schon gegen das Bestehen eines älteren degenerativen Processes mit weitgehendem Schwunde sprechen würde, sodann der doch anscheinend sehr starke Blutreichthum des Gehirns, der gleichfalls auf das Vorhandensein eines acuten Vorganges hinzuweisen scheint.

Leider ist auch die Untersuchung des zweiten Falles sehr unvollständig. Auch hier war bei der Autopsie der grosse Blutreichthum aufgefallen. Bemerkenswerther Weise war es hier zu keiner Erweiterung dẹ Seitenventrikel gekommen, während allerdings ein Untergang von nervöser Substanz durch die Verschmälerung der Gyri des Stirnhirns sich geltend machte. Die Untersucbung nach Exner ergab den für die Paralyse characteristischen Befund: Starker Faserschwund in der Rinde des Stirnhirns bei wohl erhaltenem Fasernetz in der Rinde des Cuneus. Auffallen könnte höchstens, dass der Faserschwund im Gyr. front. I noch stärker war als im Gyr. rectus. Im Rückenmark finden wir einen sklerosirenden Process, der allem Anscheine nach nicht alt ist; es spricht hierfür, worauf vorher bereits hingewiesen wurde, der Reichthum an protoplasmareichen Neurogliazellen innerhalb. der verbreiterten Septen und das Fehlen grösserer Mengen jener derberen Gliafasern. Ausserdem ist der ganze Process überhaupt nicht sehr intensiv, was schon daraus herrorgeht, dass er in den Weigert'schen Präparaten nur grade erkennbar ist. Es traten bei dem am 27. Mai verstorbenen v. G. nach dem Anfall von Bewusstlosigkeit am 20. April besorgnisserregende Erscheinungen auf. Einige Monate vorher war er jedoch schon reizbar und unmotivirt lustig. Wir werden daher in der Annahme nicht fehlgehen, dass die Veränderungen in dem Rückenmark auch schon in dieser Zeit in der Entwickelung begriffen waren, und dass sich zugleich mit denselben pathologische Processe in dem Gehirn herausgebildet haben, als deren Folge die Reizbarkeit und unmotivirte Lustigkeit zu betrachten wäre.

Erwähnen möchte ich noch, dass als luetisch zu bezeichnende Veränderungen im Centra]nervensystem nicht aufgefunden wurden. Ebenso fehlten an den Gefässen des Centralnervensystems atheromatöse 
Processe, die allerdings in der Aorta in diffuser Ausbreitung anzutreffen waren.

Ebenso wie bei den beiden ersten Gehirnen fiel auch bei dem dritten Kranken H. die starke Füllung der Gefässe auf. Für die Acuität des ganzen Processes dürften auch die ausgedehnten pachymeningitischen Veränderungen sprechen. Auffalleu muss übrigens auch die trotz der frühzeitigen Autopsie vorhandene ausserordentlich weiche Consistenz des Centralnervensystems, die im Rückenmark sogar zu einer vollständigen Erweichung geführt hatte. Desgleichen wies. der an den weichen Häuten des Rückenmarkes erhobene Befund auf einen relativ acuten Process hin. Dieselben zeigten einen abnormen Kernreichthum und eine mässige Rundzelleninfiltration. Die Gefässwandungen waren verdickt, an einzelnen fanden sich ausgesprochene endarteriitische Processe. Ueber die Natur und die Entstehung der in den weichen Häuten aufgefundenen eigenthümlichen Körperchen habe ich mir ein Bild nicht machen können. Kalkeinlagerungen waren es nicht, aller Wahrscheinlichkeit nach sind dieselben doch wohl aus Umwandlungen der Gefässwandungen hervorgegangen und aus Stoffen hyalinartiger Natur zusammengesetzt.

Im Rückenmark treffen wir auf zwei miteinander nicht im Zusammenhang stehende Processe. Einmal handelt es sich um Vorgänge degenerativer Natur, wie wir sie regelmässig bei der Paralyse antreffen. Es ist zu einer ziemlich ausgedehnten Degeneration in den H.Str. gekommen, mit welcher eine Degeneration der H.W. Hand in Hand geht. Entsprechend dieser H.St. Degeneration ist es zu einer Erkrankung der: Clarke'schen Säulen und einem Untergang der aus den H.Str. in die H.H. einstrahlenden Fasern gekommen. Auch in den am stärksten degenerirten Stellen war noch eine Zahl von Fasern erhalten, man musste daher aus dem.ganzen Bilde den Eindruck gewinnen, dass es sich auch bier um einen subacuten Process handelt, dessen Beginn wohl nur mehrere Monate zurückreicht. Ich habe bereits vorher darauf hingewiesen, dass uns exacte Merkmale für die Zeitbestimmung. derartiger Processe feblen. Auch hier war der degenerative Process in voller Weiterentwicklung, und zwar erstreckte er sich, wie die Gieson'schen Präparate zeigten, nicht nur auf die H.Str. sondern anch auf die S.St. - Ausserdem liessen sich pathologische Veränderungen schwerer Art an den Ganglienzellen der Vorderbörner nachweisen. Neben diesen Veränderungen fanden sich jene kleinen, aus einer mebr oder minder grossen Zahl starkgeschwollener Axencylinder bestehender Herde. Hier handelte es sich augenscheinlich um einen ganz acuten Process und zwar um eimen Process, der mit den sonstigen Veränderungen 
innerhalb des Rückenmark nichts zn thun hat. Wie ich bereits oben erwähnte, habe ich scbon früher einmal Gelegenheit gehabt, den gleichen Befund in einem andern Falle zu erheben. Es handelt sich in diesen Herden augenscheinlich um Processe myelitischer Natur. Es will mir nicht ausgeschlossen erscheinen, dass dieselben mit den zum Tode führenden septischen resp. pyaemischen Processen im Zusammenhang steben.

Der Hirnstamm bot keine irgendwie besonders hervorzuhebenden Befunde dar. Die Degeneration der H.St. liess sich in den Stamm als eine schmale degenerirte Zone zwischen den Kernen der Burdach'schen und der Goll'schen Stränge hinein verfolgen. Auffallend war der ausserordentlich grosse Kerureichthum der Granulationen auf dem Boden des 4. Ventrikels, auch in ihm könnte man wohl ein Zeicben für die Frische des ganzen Processes erblicken. Auch der Hirnbefund war in der Richtung auffallend, als der grosse Kernreichthum der weichen Häute, die starke Füllung der Gefässe innerhalb derselben und innerhalb der Gehirnsubstanz, die starke Ansammlong von Kernen in den Wandungen und in der Umgebung der Gefässe gleichfalls darauf hinwiesen, dass wir es hier nicht mit dem gewöhnlichen chronischen paralytischen Processe zu thun haben. In derselben Richtung würde der durchaus nicht vollständige Ausfall von Rindenfasern zu verwerthen sein. Es begann bei dem p. H. die Erkrankung im Herbst 1899, Ende December trat die stärkere Erregung auf und im Januar entwickelte sich dann der deliriumartige Zustand, in welchem er am 23. Januar zu Grunde ging. Es würde sich somit der anatomische Befund ganz gut mit dem klinischen Bilde decken.

Einen ganz besonders eigenartigen Befund ergab in dem 4. Falle die Untersuchung des Centralnervensysterns. Auch hier wiesen die weichen Häute des Rückenmarks pathologisehe Veränderungen auf, die den chronischen entzündlichen Processen zugerechnet werden müssen. Veränderungen luetischer Art fehlten. In schwerer Weise waren die H.Str. erkrankt, die zum grössten Theile degenerirt waren. Dabei war es nicht ein vollkommen einheitlicher Process, der sich in den H.Str. ausgebreitet hatte. Einmal fanden sich Veränderungen vor, die durchaus den Character der cbronischen Sklerose an sich trugen und sich über die ganze Länge des Rückenmarkes erstreckten: eine von unten nach oben zu an Stärke abnehmende Degeneration der Fasern der H.W. und eine gleichfalls an Ausdehnung von unten nach oben abnebmende Degeneration im Gebiete der H.St., die sich im Hinblick auf ihre Ausbreitung im wesentlichen als eine Fortsetzung der Wurzeldegeneration zu erkennen gab. Dementsprechend Faserschwund in den Clarke'schen 
Säulcn, Untergang der in die H.H. einstrahlenden Fasern. Diese Sklerose fand ihre Fortsetzung in den Stamm hinein, woselbst sie sich als ein schmaler von hinten aussen nach vorne innen ziehender Streifen zwischen Goll'schen und Burdach'schen Kerne präsentirte. Wir würden hier also eine Degeneration vor uns haben, die von der Sklerose bei der Tabes in nennenswerthen Punkten nicht abweicht, und von der wir nach dem ganzen Aussehen des sklerosirten Gewebes annehmen müssen, dass es sich in ihr nicht mehr um einen frischen Process handelt. Neben derselben findet sich ein etwas andersartiger Process, der im Gegensatze zu diesem grade deu Eindruck eines ganz acuten, floriden Processes macht. Es handelt sich freilich nicht eigentlich um ein Nebeneinanderbestehen dieser beiden Processe im räumlichen Sinne, indem nämlich einmal der chronisch sklerosirende Process scharfe Grenzen nicht hat, sondern unmerklich in die Umgebung übergeht, und andererseits der floride Process sich auch innerhalb der sklerosirten Partieen an allen den Stellen abspielt, an denen noch Nervenfasern vorhanden sind, und die Sklerose das ursprüngliche Gewebe noch nicht vollkommen erdrückt hat. Ich habe vorher diese Veränderungen, die mich zu der Annahme veranlassten, dass es sich hier um einen ganz acuten Process handeln müsse, so eingehend geschildert, dass ich mich hier ganz luru fassen kann. Es dürfte schwer sein, diesen Process zu classificiren, ihn den gewöhnlichen Sklerosen zuzurechnen, dürfte kaum angehen, und ebensowenig kann man ihn wohl so ohne weiteres den myelitischen Processen einreihen, denen er allerdings nahe steht; erwähnen möchte ich aber ausdrücklich, dass von einer Auswanderung von weissen Blutkörperchen nichts wahrznnehmen ist. Mit Recht freilich werden wir annehmen können, dass das Endproduct auch dieses Processes schliesslich eine Sklerosirung des Gewebes sein würde. Wir müssen ja vermuthen, dass ihre Reste theils direct, theils indirect durch die vorherbeschriebenen Zellen, die ja nichts anderes als die gewöhnlich als Körnchenzellen bezeichneten Gebilde sind, weggeschwemmt werden, dass die vorläufig noch protoplasmareichen Neurogliazellen Fibrillen produciren, protoplasmaarm werden und so den bekannten Gliafilz abgeben.

Vor nicht langer Zeit konnte ich einen dem vorliegenden in einzelnen Punkten ähnlichen Befund beschreiben ${ }^{1}$ ) und möchte hier Gelegenheit nehmen in Kürze auf einen mir gemachten Einwand einzugehen. Herr Dr. Storch war so liebenswürdig meine damalige Beschreibung

1) Ein Beitrag zur pathologischen Anatomie der Myelitis. Monatsschrift für Psych, and Neurol. 99. 
in eingehender Weise in dem Centralblatt für Neurologie und Psychiatrie zú referiren und seine von der meinigen zum Theil abweichende Auffassung zu äussern. Ich bin ihm für diese Anregung sehr dankbar und habe Gelegenheit genommen, meine Präparate nochmals von dem von Herrn Dr. Storch geäusserten Gesichtspunkte aus durchzusehen. Ich kann mich jedoch der von Herrn Dr. Storch geäusserten Meinung auch jetzt nicht anschliessen. Herr Dr. Storch macht darauf aufmerk. sam, dass in jenem Befunde an einer Stelle sich eine Leucocytheninfiltration vorgefunden habe, und weist darauf hin, dass es wohl nicht die Neurogliazellen siud, die an dem Abbau der nervösen Substanz betheiligt sind, sondern eben die aus den Blutgefässen ausgewanderten Leucocythen. Es ist ja nicht zu bezweifeln, und darauf habe ich ja seinerzeit aufmerksam gemacht, dass bei vielen krankhaften Processen Leucocythen aus den Gefässen auswandern, eine phagocythäre Rolle spielen und sich in jene Gebilde unwandeln, die uns als Körnchenzellen bekannt sind. In dem seinerzeit von mir untersuchten Rückenmark fanden sich nun aber diese Exsudatzellen nur ganz vereinzelt, während an den anderen Stellen absolut nichts von denselben zu entdecken war. Meine Auffassung musste mir aber um so unbedenklicher erscheinen, als ich genau dieselben Beobachtungen auch bei Processen gemacht hatte, bei welchen ein entzündlicher Vorgang nach unseren Anschauungen vollkommen ausgeschlossen ist. So habe ich in jener Arbeit (S. 365) eigens erwähnt, dass ich ein gleiches Verhalten bei einem Falle von absteigender Degeneration d. Py. S. B. zu beobachten Gelegenheit hatte, eine Beobachtung, die ich übrigens auch in der Folge noch mehrfach zu wiederholen Gelegenheit hatte. Sodann hat Herr Dr. Storch darauf aufmerksam gemacht, dass diese den Axencylindern anliegenden Zellen mit den Neurogliazellen keine Formähnlicbkeit haben. Es ist dies richtig, wenn man diese Zellen mit den entwickelten Neurogliazellen vergleicht. Wesentlich anders aber gestaltet sich das Bild, wenu man jene bei den Wucherungen der Neuroglia auftretenden mehr kubischen, doch auch der Neuroglia angehörenden Zellen berücksichtigt. Ich muss dabei freilich zugeben, dass die Entstehung dieser Zellen noch in Dunkel gehüllt ist. Schliesslich betont Herr Dr. Storeb, wie unwahrscbeinlich es erscbeinen müsse, den Neurogliazellen die Fähigkeit des Wanderns zuschreiben zu wollen. Bei dem Anlagern der Neurogliazellen an die Axencylinder würde es sich aber um eine Wanderung garnicht handeln, hier würde vielmehr nichts anderes vorliegen, als dass die wuchernden Neurogliazellen in den Raum der Markscheicen hineindringen und so mit dem Axencylinder in Berührung treten. Eine Wanderung würde auch nicht vorliegen, wenn diese Zellen nach Aufnahme von Axencylin- 
derresten zu Grunde gehen, zerfallen, und ihre Trümmer weggeschwemmt werden. Von einem Wanderu würde also nur dann gesprochen werden können, wenn wir jene Körnchenzellen in's Auge fassen, welche wir an einer von dem Orte des Unterganges der Nervenfaserm entfernten Stelle, also z. B. in den Lymphscheiden der Gefässe antreffen. Bei der Beurtheilung dieser Frage würde aber vor allem festzustellen sein, in wie weit hierbei diese Zellen activ thätig sind, da es sehr wohl möglich ist, dass ihre Locomotion passiv ist und durch den Lymphstrom veranlasst wird.

Neben den degenerativen Vorgängen in dem Gebiete der H.St. und den durch dieselben secundär bedingten Veränderungen in der grauen Substanz fanden sich noch eine Reihe weiterer pathologischer Processe in dem Rückenmark vor. Die sicherlich erst submortal entstandenen kleinen Blutungen möchte ich dabei hier nicht weiter erwähnen. Von Bedeutung ist jedoch die Betheiligung der Py. S.St. an der Erkrankung. Diese Erkrankung ist ja auch als ein degenerativer Vorgang aufzufassen, derselbe ist, nach dem Aussehen der erlkrankten Parthie zu urtheilen, relativ frisch, hat jedoch nichts von jenem so acuten Processe wie ihn ein Theil der Veränderungen in den H.St. aufweist, an sich, sondern zeigt "ein Bild, wie wir es oft genug bei dem Beginne sklerosirender Processe finden. Als von ihm abhängig haben wir die Degeneration in den Seitenhömern der grauen Substanz aufzufassen. Daneben lassen sich auch noch über die anderen Gebiete der weissen Substanz zerstreut, einzelne erkrankte Fasern auffinden. Schliesslich wären noch die mit der Nissl'schen Methode erhobenen Befunde hier zu besprechen. Wir werden hier ganz besonders vorsichtig vorgehen müssen, da dem Tode eine schwere Allgemeinerkrankung vorausgegangen ist, und solche schweren Erkrankungen schon an und für sich im Stande sind, derartige Veränderungen hervorzubringen. Trotzdem möchte ich in diesem Falle doch annehmen, dass diese Veränderungen, die Erscheinungen des Zerfalls an den multipolaren V.H. Ganglienzellen, und das abnorme Verhalten der Strang- der Hinterhornzellen und der Zellen der Clarke'schen Säulen mit dem paralytischen Processe im Zusammenluang stehen.

Die Untersuchung des Hirnstamms förderte kein besonciers bemerkenswerthes Resultat zu Tage, zu erwähnen wäre nur, dass auch hier von einer stärkeren kleinzelligen Infiltration nichts aufzufinden war, und dass die Gefässe, speciell auch die Arteria basilaris von peri- oder endarteriitischen Veränderungen frei waren.

An den weichen Häuten des Gehirns war die auffallend starke Infiltration mit Rundzellen bemerkenswerth. Dieselbe war zwar an Stärke 
in keiner Weise mit der Infiltration der tuberculösen oder syphilitischen Processe zu vergleichen, wies aber doch einen erbeblicheren Grad auf, als er im allgemeineu der Paralyse eigen ist. Wir werden in derselben wohl nicht mit Unrecht einen Ausdruck für die Acuität des Processes zu erblicken haben. Ebenso fällt die Stärke der Infiltration in den Wandungen und in der Umgebung der Hirngefässe auf; erwähnt möge auch noch die ganz allgemeine sich auf das Rückenmark erstreckende Füllung der Gefässe mit Blut werden. Wie immer war es auch hier in der Rinde zu. einer Neubildung von Gefässen durch Schlingen und Sprossenbildung gekommen. Für einen recht acut verlaufenden Process dürfte auch das Verhalten der Glia innerhalb des Stirubirns sprechen, indem die Zahl jener protoplasmareichen Gliazellen sehr gross war, und sich in dem Gewebe bereits eine erhebliche Zahl jener bei der van Gieson'schen Methode ganz blass bleibenden Körnchenzellen vorfand. Daneben freilich bestanden auch bereits Veränderungen, die mehr ein chronisches Gepräge an sich hatten, so z. B. der sklerosirende Process in den obersten Schichten der Rinde. Dabei ergab die Untersuchung der Rinde in Bezug auf die Verarmung an Nervenfasern einen Befund, wie wir ihn bei weit vorgeschrittenen Paralysen vorfinden; wir müssen hierbei freilich eingestehen, dass wir Untersuchungen über die Schnelligkeit, mit welcher diese Fasern zu Grunde gehen, nicht besitzen.

Bei dem Patienten R. traten die ersten Krankheitserscheinungen von Seiten des Centralnervensystems im April 1896 auf, und zwar stellten sich Erscheinungen ein, die als Tabes dorsalis gedeutet wurden. Sicherlich waren in jener Zeit die skJerotischen Veränderungen in dem Rückenmark schon lange entwickelt, dieselben rechtfertigen die Diagnose der Tabes in soweit als es sich ja um eine degenerative Erkrankung der H.St. handelte. Auffallend bleibt dabei jenes in der Anamuese angegebene Symptom, dass Patient eines Norgens zum Gehen vollkommen unfähig war. Es fehlt leider jede Angabe, in wiefern der Patient die Herrschaft über seine unteren Extremitäten verloren batte. Da der Patient allem Anschein nach aber seine unteren Extremitäten sehr bald wieder gebrauchen konnte und auch späterhin keine klinischen Erscheinungen darbot, welche auf das Vorhandensein einer Störung innerhalb der motorischen Bahnen hindeuten, und auch ein pathologischer Befund, der für das Vorhandensein eines zu einer gewöhnlichen Paraplegie führenden Processes spräche, fehlte, müssen wir wohl annehmen, dass es sich damals auch nicht um einen organischen, die motorische Bahn treffenden, und zu einer Lähmmng führenden pathologischen Vorgang gehandelt hat. Wahrscheinlich dürfte es sich um ein bei der Tabes ja zuweilen beobachtetes, in Folge einer plötzlichen Schwäche- 
anwandlung auftretendes Zusammenbrechen der Beine gehandelt haben. Fraglich dürfte es sein, ob auch damals bereits jene anderen, ich will der Kürze halber einfach sagen, myelitisartigen Veränderungen im Gebiete der H.St. bereits bestanden haben. Diese Frage dürfte zu verneinen sein. Einmal weist schon der pathologisch anatomische Befund darauf hin, dass hier ein acuter Process obwaltet, dann aber müssten derartig weit ausgedehnte Processe schon früher zu viel folgenschwereren Erscheinungen geführt haben. So wird man zu der Annahme gedrängt, dass sich dieser Process erst in der letzten Zeit vor dem Tode entwickelt hat. Ich habe vorher bereits darauf hingewiesen, dass es sehr schwer ist, diesen Process zu classificiren. Bei jedem derartigen Versuche müsste ja eigentlich die ganze Frage über die Natur der Myelitis sowie der als Sklerose bezeichneten Processe aufgerollt werden; Fragen, die bisher eine endgültige, allgemein anerkannte Lösung nicht gefunden haben. In dem vorliegenden Falle wird es sich vor Allem um die Entscheidung handeln, ob wir hir zwei verschiedenartige Processe im Gebiete der H.St. vor uns haben, oder nur einen Process in verschiedenen Alters- resp. Entwickelungs-Stadien. Ich selbst möchte entschieden das letztere anuehmen, wenngleich ich rorher, um mich kurz ausdrücken zu können, die acut erscheinenden Veränderungen als myelitisartige den chronischen gegenüber gestellt habe. Es würde sich demnach um denselben Process handeln, der chronisch begounen und damn einen acuten Nachschub erfahren hat. Bezeichnen müssten wir den ganzen Process als einen degenerativen, als einen krankhaften Vorgang, der die nervösen Elemente befallen nnd secundär die Glia in Mitleidenschaft gezogen hat. Das Auftreten der so zahlreichen Körnchenzellen, die meiner Auffassung nach in ihrer weitaus grössten Zahl aus den Gliazellen hervorgegangen sind, würde dann eben durch das plötzliche und. weitverbreitete Zugrundegehen der Nervenfasern bedingt sein.

Ebenso wie diese Veränderungen im Rückenmark scheinen auch eine Reihe von pathologischen Processen innerhalb des Gehirns neueren Datums zu sein; es spricht hierfür das Fehlen ausgedehnter sklerotischer Processe in der Rinde, der Reichthum an protoplasmareichen' Gliazellen, die kleinzellige Infiltration und der Kernreichthum in der Umgebung der Gefässe und innerbalb der weichen Häute, sowie das anscheinend ganz acute Zugrundegehen von Nervenfasern innerbalb der weissen Substanz, auf welches das Vorhandensein der zahlreichen Körnchenzellen hindeutet. Einzelne sklerosirnde Processe scheinen aber auch hier bereits älteren Datums zu sein. Auf welche Zeit der Beginn des Faserschwundes zu verlegen ist, entzieht sich unserer Beurtheilung, 
höchstens könnte man annehmen, dass dieser so erhebliche Ausfall yon Fasern erst in der letzten Zeit aufgetreten ist, da er sonst doch wohl schon früher klinische Erscheinungen hervorgerufen hätte.

Bei dem Kranken haben sich die ersten Krankheitserscheinungen auf psychischem Gebiete Ende Juni kurz nach einer intensiven antiIuetischen Behandlung bemerkbar gemacht, um dann in rapider Weise zuzunehmen und bereits am 17. Juli zum Tode zu führen. Man wird hier doch wohl an einen ursächlichen Zusaromenhang zwischen der Schmierkur und der acuten Verschlimmerung denken müssen. Ich habe vorher bereits einen anderen Fall angeführt, in welchem gleichfalls nach einer Schmierkur eine rapide, alsbald zum Tode führende Verschlimmerung auftrat. Aehnliche Erfahrungen sind ja auch sonst nicht so selten gemacht worden, und haben dahin geführt, dass vou vielen Seiten von der Einleitung einer mercuriellen Kur gewarnt worden ist. Die meisten Beobachter haben sich dabei leider damit begnügt ihre Meinung zu sagen, ohne das ihrer Ansicht zu Grunde liegende Beobachtungsmaterial zu veröffentlichen. So kommt es, dass sich in der Literatur allerdings nur wenige, hierher gehörige Fälle haben auffinden köunen. Sehr prägnant sind die beiden von $Z_{a} c_{h e r}{ }^{1}$ ) veröffentlichten Beobachtungen, die mir allerdings nur im Referat zugänglich gewesen sind. In beiden Fällen handelte es sich um Kranke, die nach kurzem Bestehen der Erscheinungen der Paralyse einer Schmierkur unterzogen wurden, eine acute Verschlimmerung ihres Leidens erlitten and unter deliriumartigen Erscheinungen zu Grunde gingen.

Allerdings sind in der neneren Zeit auch wieder Beobachtungen veröffentlicht worden, in welchen die antiluetische Kur von gutem Erfolge gewesen sein soll. Es schien mir desto mehr wünschenswerth, auch wiederum einmal anf die eventrellen ungünstigen Folgen dieser Behandlung aufmerksam zu machen.

Im wesentlichen lässt sich somit der pathologisch anatomische Befund in den 4 letzten von mir aufgeführten Krankheitsfällen mit dem klinischen Krankheitsverlaufe wohl vereinbaren. Den ersten derselben werden wir freilich mangels jeder genaueren Untersuchung bier ausser Acht lassen müssen. In dem 2. und 3. Falle machen die aufgefundenen Veränderungen innerhalb des Centralnervensystems, soweit sich dies bei unseren bisherigen Kenntnissen beurtheilen lässt, durchaus den Eindruck,

1) Zwei Fälle von sogenanntem Delirium acutum bei Dementia paralytica, hervorgerufen durch eine Schmiereur. Psychiatrische Bladen Bd. 11. Lief. 1. Referat in der Zeitschr. für Psych. Bd. 50. 
als ob sie in ihren Anfängen nicht über wenige Monate zurückreichen. Etwas anders liegen die Verhältnisse in dem 4. Falle. Hier ist der sklerosirende Process innerhalb der HSt. des Rückenmarkes sicherlich älteren Datums. Aber auch hiermit stimmen die klinischen Erscheinungen überein, denn als die ersten Krankheitserscheinungen auftraten, musste ja der Process in dem Rückenmark bereits eine gewisse Ausdehnung haben. Wabrscheinlich ist es sogar, dass derselbe eine lïngere Zeit hindurch vollkommen symptomlos verlaufen ist. Wir können daher eigentlich, wenn wir ganz strenge und correct sein wollen, auf Grund dieses Befundes diesen Fall nicht ohne weiteres der galoppirenden Paralyse zurechnen. Er würde vielmehr eigentlich den mehr chronischen Paralysen mit deliriumartigen Endstadien an die Seite zu stellen sein. Er zeigt übrigens auf das deutlichste, dass zur Beurtheilung des ganzen Krankheitsprocesses die mikroskopische Untersuchung des Centralnervensystems unerlässlich ist, und dass somit die unter der Bezeichnung der galoppirenden Paralyse veröffentlichten Fälle, in welchen die Untersuchung nicht in dieser Weise durchgeführt ist, als vollkommen beweislkräftig nicht angesehen werden können; so z. B. die Fälle von M endel'1), Zacher ${ }^{2}$, Kundt ${ }^{3}$ ), Brassert ${ }^{4}$ ) und Sioli ${ }^{5}$ ).

Ebenso aber wie dieser 4 . Fall einen Uebergang zu der vorher geschilderten Verlaufsform, wie sie uns die Kranken Franz H. und Fritz H. aus Cassel darboten, darstellt, lassen sich auch gewisse Uebergangsformen von der Verlaufsart bei den anderen 3 Kranken $z u$ den sonstigen acut verlaufenden Formen auffinden. Es ist dies ja auch nicht anders denkbar, denn schliesslich handelt es sich ja immer um denselben, wenn auch vielgestaltigen Krankheitsprocess. Trotzdem dürfte es sich der schnellen Verständigung wegen empfehlen, die schnellverlaufenden Paralysen den gewöhnlich so chronischen Formen gegenüber zu stellen. Unter diesen acut verlaufenden Paralysen könnte man, wie ich es auf Grund der klinischen Bilder gethan habe, von schnellverlaufenden, acuten Paralysen und von galoppirenden, foudroyanten Paralysen sprechen. Während die erstgenannten nur dadurch ausgezeichnet sind, dass das Leiden einen abgekürzten, stürmischen Verlauf nimmt, würden die letztgenannten dadurch characterisirt sein, dass bei ihnen nach einem kurzen

1) loc. est 317.

2) Neurol. Centralbl. 1891.

3) Neurol. Centralbl. 1894.

4) Zeitschr. für Psych. Bd. 55.

5) Charité-Annalen. IV. Jahrgang. 1877. 
478 Prof. Dr. Buchholz, Ueber die acut verl. Erlkr. an Dementia paralytica.

Prodromalstadium Erscheinungen vom Character des Delirium acutum auftreten, unter welchem der Kranke rapid zu Grunde geht. Neben diesen Verlaufsformen würden jene Fälle noch eine besondere Stellung einnehmen, in welchen nach einem mehr chronischen Krạnkheitsverlaufe plötzlich dieser deliriumartige Symptomencomplex auftritt und das Schicksal des Kranken bessiegelt.

Ich möchte nicht unterlassen, meinem verehrten bisherigen Chef und Lehrer Herrn Prof. Tuczek auch an dieser Stelle meinen Dank für die Ueberlassung des dieser Arbeit zu Grunde liegenden Materials auszusprechen. 


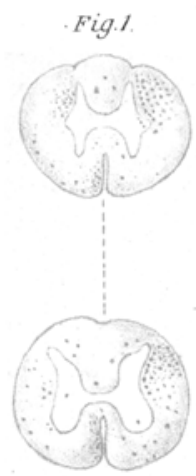

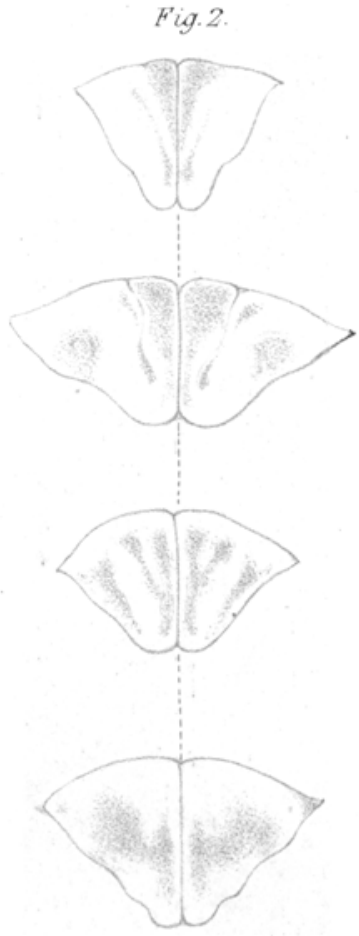

Fig. 4

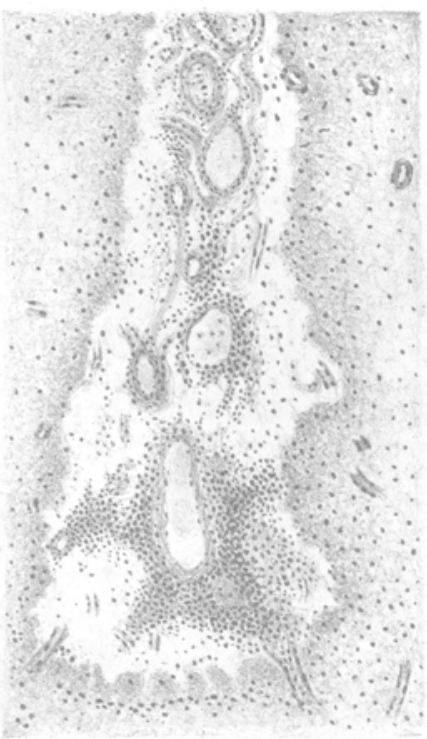

Fig.3.
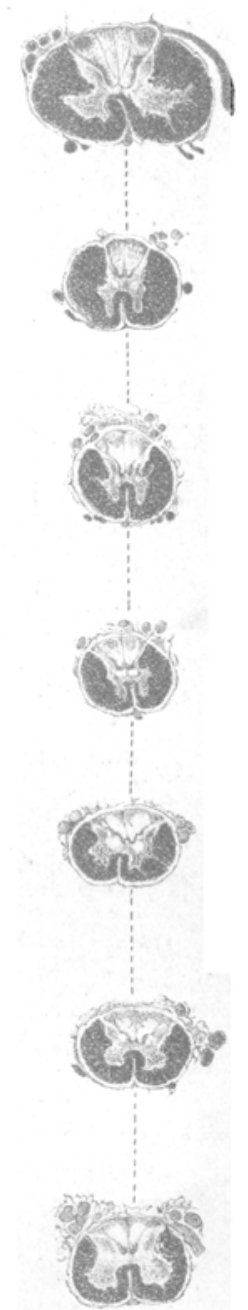